FEDERAL RESERVE BANK OF SAN FRANCISCO

WORKING PAPER SERIES

\title{
UI Generosity and Job Acceptance: Effects of the 2020 CARES Act
}

\author{
Nicolas Petrosky-Nadeau and Robert G. Valletta \\ Federal Reserve Bank of San Francisco
}

June 2021

Working Paper 2021-13

https://www.frbsf.org/economic-research/publications/working-papers/2021/13/

\section{Suggested citation:}

Petrosky-Nadeau, Nicolas, Robert G. Valletta. 2021 "UI Generosity and Job Acceptance: Effects of the 2020 CARES Act," Federal Reserve Bank of San Francisco Working Paper 2021-13. https://doi.org/10.24148/wp2021-13

The views in this paper are solely the responsibility of the authors and should not be interpreted as reflecting the views of the Federal Reserve Bank of San Francisco or the Board of Governors of the Federal Reserve System. 


\title{
UI Generosity and Job Acceptance: Effects of the 2020 CARES Act
}

\author{
Nicolas Petrosky-Nadeau \\ Federal Reserve Bank of San Francisco \\ Robert G. Valletta \\ Federal Reserve Bank of San Francisco
}

May 28, 2021*

\begin{abstract}
To provide economic relief following the onset of the COVID-19 pandemic, the U.S. CARES Act granted an extra $\$ 600$ per week in unemployment insurance (UI) benefit payments from late March through July 2020. This unprecedented increase in UI generosity caused weekly benefit payments to exceed prior earnings for most recipients, raising concern that many would be unwilling to accept job offers, slowing the labor market recovery. To assess the impact of the UI supplement, we analyze the job acceptance decision in a dynamic framework in which job seekers weigh the value of a job against remaining unemployed, accounting for the perceived state of the labor market and expected weeks of UI benefits. We derive a reservation level of benefit payments at which an individual is indifferent between accepting and refusing a job offer at their prior wage. Calculating the reservation benefit and comparing it to imputed benefit payments for a wide range of U.S. workers suggests that only a small fraction would turn down an offer to return to work at their previous wage under the CARES Act expanded UI payments. We supplement this quantitative assessment of reservation benefits with direct empirical analysis of labor force transitions using matched Current Population Survey (CPS) data, linked to annual earning records from the CPS income supplement to form UI replacement rates. The results show moderate disincentive effects of the $\$ 600$ supplemental payments on job finding rates and by extension small effects of the $\$ 300$ weekly supplement available during 2021.
\end{abstract}

JEL Classification: J64, J65.

Keywords: Unemployment, unemployment insurance, job acceptance, COVID-19, CARES Act.

*Petrosky-Nadeau: FRB San Francisco, 101 Market Street, San Francisco CA 94105; e-mail: Nicolas.PetroskyNadeau@sf.frb.org. Valletta: FRB San Francisco, 101 Market Street, San Francisco CA 94105; e-mail: rob.valletta@sf.frb.org. Olivia Lofton provided excellent research assistance. This paper includes a significant expansion of content released in an earlier working paper by Petrosky-Nadeau (FRBSF Working Paper 2020-28, August 2020), "Reservation Benefits: Assessing Job Acceptance Impacts of Increased UI Payments." The views expressed are those of the authors and do not necessarily reflect the views of the Federal Reserve Bank of San Francisco or the Federal Reserve System. 


\section{Introduction}

The Coronavirus Aid, Relief, and Economic Security (CARES) Act, through the Pandemic Unemployment Compensation (PUC) provision, provided an additional $\$ 600$ per week to supplement regular unemployment insurance (UI) benefits during the initial outbreak of COVID-19 from late March though the end of July 2020. The generosity of the program raised concerns it could delay the speed of the labor market recovery as some individuals, earning more per week unemployed with the additional UI support than on the previous job, would reject offers to return to work. This reflects the standard moral hazard effect of UI benefits on job search (Baily 1978, Chetty 2008). ${ }^{1}$

This concern overlooks the dynamic nature of employment, comparing static weekly earnings to benefit amounts instead of the expected payoff of an entire job spell to that of remaining unemployed. This paper uses a dynamic model of job acceptance decisions to derive the level of benefits necessary for workers to be indifferent between accepting a job offer at the previous wage and rejecting it to remain unemployed conditional on the remaining number of weeks of unemployment compensation. An offer is accepted if the current level of benefits is below this reservation benefit.

For a given job offer, the level of the reservation benefit is determined by: (i) the expected duration of the employment spell for an accepted job - longer lasting jobs have a greater value and are rejected only for commensurately more generous unemployment insurance payments; (ii) the rate of arrival of new job offers - in a depressed labor market, when job offers are few and far between, any job offer is costly to refuse, raising the reservation benefit amount, and; (iii) the duration of benefits remaining - an additional week of benefits raises the opportunity cost of accepting an offer and lowers the reservation benefit level. In the limit of unbounded UI duration the reservation benefit converges to the wage offered. Conversely, with one week remaining of UI payments, the reservation benefit is always above the prior wage.

We apply the reservation benefit concept to the period covered by the provisions in the CARES Act, including the extension of benefit payments for up to 52 weeks with the Pandemic Emergency Unemployment Compensation (PEUC) and state emergency extensions. We use data from the Bureau of Labor Statistics' (BLS) Current Population Survey (CPS) to impute reservation benefit levels for workers in different skill groups (education), in different occupations, and across U.S. states. Our quantitative analysis suggests that only a small fraction of UI recipients, in a narrow set of types, would refuse an offer to return to work at their previous pay. A typical high school educated worker, with $\$ 800$ in weekly earnings and UI replacement rates (UI benefit amounts relative to prior wages) near 125\% in early May 2020, would not have been deterred from accepting a job offer. In fact, the PUC payment would need to increase by an additional $\$ 250$ per week before such individuals would consider rejecting the job offer. From the perspective of the first week of June 2020, with 8 weeks of supplementary UI payments remaining and as states were moving to

\footnotetext{
${ }^{1}$ The CARES Act included two provisions that stand out relative to previous UI policy responses during recessions: it relaxed UI eligibility requirements and provided the supplemental $\$ 600$ per week in UI payments. The latter provision attracted particular attention, due to the resulting high incidence of UI payments that exceeded earnings in previous jobs (see Ganong, Noel and Vavra, 2020).
} 
re-open their economies, only workers in the lowest paid occupation (food services, with typical earnings of $\$ 460$ per week) would be roughly indifferent between accepting a job offer at their previous wage and remaining unemployed. For all other occupations, replacement rates over 100\% under the CARES Act were unlikely to be the cause of rejected job offers. The value of a sustained job, especially in a depressed labor market, significantly outweighs the value of the temporary additional UI income.

We complement these estimates with direct empirical tests to assess the extent to which the $\$ 600$ supplemental weekly payments affected job finding rates and other labor market flows. We implement a difference-in-differences regression framework to assess whether the change in jobfinding rates and other labor market transitions between the pre-CARES and CARES periods is larger for individuals who have higher UI replacement rates as a result of the supplemental payments. Our value added relative to prior analyses of the potential disincentive effects of the CARES Act supplemental payments arises from two specific features of our analyses: (i) we exploit individual variation in UI replacement rates; (ii) we directly assess the labor market transitions, in particular job-finding rates (exits from unemployment to employment), that may be affected by the moral hazard effect of UI benefit generosity. Our regression analyses rely on labor market transition data formed using data on individuals matched across consecutive monthly CPS files. We use data for early- to mid-2020 only, to focus on the impact of the extra $\$ 600 /$ week of UI payments specified by the CARES Act and available from late March through the end of July. We combine the monthly CPS data with estimated UI replacement rates that rely on the calculator developed by Ganong, Noel and Vavra (2020) and annual earnings data from the CPS Annual Demographic Supplement for the individuals observed in our matched monthly CPS data. Our results show moderate, imprecisely estimated disincentive effects of the very large increase in UI replacement arising from the $\$ 600$ weekly supplemental payments under the CARES Act. The size of these effects is broadly consistent with the preceding analyses based on the reservation benefits framework. We also extrapolate those findings to assess the potential impacts of the $\$ 300$ weekly supplemental UI payments that have been available in 2021. This reduced supplement likely had small but noticeable effects on job search and worker availability in early 2021.

Our analyses build on prior work and are broadly consistent with existing results. Early studies on the effects of the UI expansions under the CARES Act found little impact exit rates out of unemployment. Bartik et al. (2020) and Altonji et al. (2020) found that states with more generous UI systems did not experience weaker labor market rebounds during the initial phase of reopening. ${ }^{2}$ The values of the reservation benefits calculated here are in line with these findings as the additional UI income is found to deter job acceptance for only a few categories of workers, and states with the more generous UI payments also tended to have the highest reservation benefits

\footnotetext{
${ }^{2}$ There is some evidence that more generous UI payments increased separations out of employment during the pandemic. In theory, UI does not necessarily increase layoffs when there is a fall in demand (see Burdett and Hool 1983 in an implicit contract framework between a pool of attached workers and a firm which faces uncertain product demand).
} 
replacement rates. ${ }^{3}$ Taken together, the additional income provided to the unemployed through the CARES Act and subsequent legislation likely had little impact on the unemployment rate via labor supply effects in early to mid-2020 and early 2021. Rather, the additional income likely acted as an effective targeted fiscal transfer supporting aggregate demand.

These findings are consistent with research on the effects of UI extensions during prior recessions. During the Great Recession, in particular, successive extensions increased coverage from a usual 26 weeks to up to 99 weeks. A preponderance of studies based on individual worker data find negligible effects of extending the duration of UI payments on the unemployment exit rates for eligible unemployed workers. Moreover, UI extensions appear to reduce labor force exit rates of the unemployed rather then their employment probabilities, with an effect that is strongest among the long term unemployed; studies that, aggregate the individual responses to UI extensions conclude the effect on the overall unemployment rate is negligible (Rothstein 2011, Farber and Valletta, 2015, Chodorow-Reich, Coglianese and Karabarbounis, 2019). Moreover, the magnitude of the effect is highly cyclical, with little to no effect of UI duration extensions during severe recessions (Kroft and Notowidigdo, 2016). ${ }^{4}$

The literature on optimal UI emphasizes a basic equity/efficiency trade-off arising from the moral hazard effect on worker search behavior (Feldstein 1976, Baily 1978, Acemoglu and Shimer 1999, Chetty 2008, Kroft and Notowidigdo, 2016). While earlier work emphasizes the disincentive effect of UI on worker search, leading to longer unemployment spells and higher unemployment, Acemoglu and Shimer (1999) show a positive amount of UI increases output by improving the allocation of risk averse workers to high wage, high productivity jobs. ${ }^{5}$ The reservation benefit statistic developed here does not take into account risk aversion, which would increase the value of a long stream of earned income on the job compared with temporary UI payments. It is most closely related to the concept of reservation wages of Shimer and Werning (2007). This after-tax reservation wage is the take home pay required to make a worker indifferent between working and remaining unemployed. ${ }^{6}$

The rest of this paper is organized as follows. Section 2 describes the decision problem and derives a reservation benefit as a function of the state of the labor market, the wage offer and the number of weeks of UI payments remaining. Section 3 adapts the reservation benefit statistic to

\footnotetext{
${ }^{3}$ Several studies documenting the labor market disruptions from the pandemic note that job losses have been more heavily concentrated among workers that take significantly longer to find stable jobs in the future (see Gregory, Menzio and Wiczer, 2020 for example). Boar and Mongey (2020), using a quantitative framework that relates to our reservation benefits analysis, also find a likely limited impact of temporarily increased UI payments on job acceptance decisions during the pandemic.

${ }^{4}$ See Moffitt (1985) for an early study of the effect of UI on unemployment durations. Lalive, Landais and Zweimüller (2015) find contrasting results in Austrian data, arguing an extension in the duration of UI benefits undermines overall demand for labor. A related question not addressed here is the impact of UI provisions on the joint behavior of workers and firms, and in particular on the duration of employment spells (see, for instance, Feldstein 1976 and Baker and Rea 1998).

${ }^{5}$ See also Acemoglu (2001) for an analysis of the impact of UI on the composition of job and labor productivity across US states. See Hopenhayn and Nicolini (2009) for an analysis of optimal UI in asymmetric information environments in which workers experience multiple unemployment spells.

${ }^{6}$ Marinescu and Skandalis (2021), using French administrative data, find evidence of declining reservation wages (measured as a desired target wage) as exhaustion of UI benefit payments nears.
} 
the details of the CARES Act and uses data from the Current Population Survey (CPS) to calculate benefit amounts for different categories of workers. Section 4 provides the results from the empirical analyses of labor market transitions from matched monthly CPS data. Section 5 concludes.

\section{UI income and job acceptance decisions}

This section describes the problem of a risk neutral insured job seeker considering a job offer at the previous wage, $w$. It compares the present value of the job, $W_{E}(w)$, to that of remaining unemployed with UI benefits $b$ and $t$ remaining weeks of eligibility, $W_{U}(b, t) .{ }^{7}$ The decision takes into account the likely duration of the job and that of finding an alternative offer - through the probabilities of losing and finding a job $s$ and $f$, respectively - and the discounting of time at rate $r$ :

$$
\begin{aligned}
W_{E}(w) & =w+\frac{1}{1+r}\left[(1-s) W_{E}(w)+s W_{U}(b, T)\right] \\
W_{U}(b, t) & =b+\frac{1}{1+r}\left[(1-f) W_{U}(b, t-1)+f \max \left[W_{E}(w), W_{U}(b, t-1)\right]\right] \text { for } 1<t \leq T \\
W_{U}(b, 1) & =b+\frac{1}{1+r}\left[(1-f) W_{U}(0)+f \max \left[W_{E}(w), W_{U}(0)\right]\right] \\
W_{U}(0) & =0+\frac{1}{1+r}\left[(1-f) W_{U}(0)+f \max \left[W_{E}(w), W_{U}(0)\right]\right]
\end{aligned}
$$

where $T$ is the maximum duration of UI, $W_{U}(0)$ is the value of unemployment after exhaustion of unemployment benefits, $W_{U}(b, T)$ is the value of unemployment at the start of a new unemployment spell following a job loss, and for a positive wage, $\max \left[W_{E}(w), W_{U}(0)\right]=W_{E}(w) .{ }^{8}$

If employment if preferred to remaining unemployed at a date $t+1$ then, from the value functions above, the value of unemployment up to the maximum duration of UI of $T$ weeks can be re-expressed as:

$$
W_{U}(b, t)=B(t)+\left(\frac{f}{r+f}\right) W_{E}(w) \text { for } 1<t \leq T
$$

which highlights that unemployment is valued for the discounted present value of expected UI payments with $t$ weeks of eligibility remaining, $B(t)=\sum_{i=0}^{t-1} b\left(\frac{1-f}{1+r}\right)^{i}$, and the discounted value of finding a job and moving into employment.

\footnotetext{
${ }^{7}$ The exercise considers offers to return to work at the same wage. Although there is little evidence of significant wage cuts during the recession triggered by the COVID-19 pandemic, the approach developed here is straightforward to adapt to any wage offer.

${ }^{8}$ We assume that employment immediately affords eligibility to full UI whereas state UI systems have different work and earnings requirements to establish UI eligibility. Detailed derivations for all results are provided in the appendix.
} 


\subsection{Reservation benefits}

Since the value of unemployment in (5) is increasing in the weekly benefit amount, there exists a reservation benefit $b^{r}(t, w)$ to be paid out for the remaining weeks of eligibility $t$ such that an individual is indifferent between remaining unemployed and receiving that amount oraccepting a job offering pay $w$. That is, a job offer with pay $w$ will be turned down if the current level of weekly benefit payments $b$ is greater than this reservation level $b^{r}(t, w)$. Formally:

Proposition 1. The reservation benefit for an unemployed individual with tweeks of UI eligibility remaining and considering a job offer at wage w solves:

$$
W_{U}\left(b^{r}(t, w), t\right)=W_{E}(w)
$$

Given the value functions for employment and unemployment (1) and (5) the reservation benefit is

$$
b^{r}(t, w)=\frac{b^{r}(1, w)}{\sum_{i=0}^{t-1}\left(\frac{1-f}{1+r}\right)^{i}} \text { for } 0<t \leq T
$$

where

$$
b^{r}(1, w)=\left(\frac{r}{r+f}\right) W_{E}(w)=\left(\frac{r}{r+f}\right)\left(\frac{(1+r) w+s W_{U}(b, T)}{r+s}\right)>w
$$

Job seekers will accept an offer to return to work at their previous wage if weekly income from $\mathrm{UI}$ benefits is lower than their reservation level of benefits with $t$ weeks of payments remaining, $b<b^{r}(t, w)$.

For a given wage offered, the level of reservation benefits to reject the job is determined by the duration of benefits remaining $(t)$, the expected duration of the employment spell $(\approx 1 / s)$, and the rate of arrival of new job offers $(f)$. With an unbounded duration of UI payments $(T \rightarrow \infty)$ the reservation benefit is equal to the wage $b^{r}(\infty)=w$. In this limit, a replacement rate above $100 \%$ will induce workers to reject a job offer at their previous wage rate. With one week remaining, the reservation benefit $b^{r}(1, w)$ is the annuity value of the present discounted value of the job offered. It is always the case that, with a week remaining, the reservation benefit is greater than the wage offer $\left(b^{r}(1, w)>w\right)$. In other words, replacement ratios above $100 \%$ do not necessarily lower job offer acceptance rates. More generally, for UI benefit payments of finite duration, the reservation benefit $b^{r}(t)$ is declining with weeks remaining of UI benefits, trading off an additional week of benefits at the reservation level against the forgone employment value. The level of the reservation benefit depends crucially on the expected duration of the employment spell and the rate of arrival of new job offers. Longer lasting employment spells (lower $s$ ) have a greater value and are rejected only for commensurately generous unemployment insurance payments. In a depressed labor market, when job offers are few and far between (low $f$ ), any job offer is costly to refuse as new offers are hard to find. This can be seen in the discounting terms in equations (7) and (8). 


\section{Reservation benefits during the pandemic}

This section provides estimates of reservation benefits for different categories of workers during the COVID-19 recession. We adapt the general problem to reflect institutional details from the CARES Act and then usie micro data from the CPS to obtain the relevant moments entering the definition of a reservation benefit level. The main set of results are based on the experience during the recovery out of the Great Recession of 2007-09. Additional results, obtained by varying the assumptions on the expected durations of unemployment and employment spells, are provided and are meant to capture bounds on reservation benefit levels at different horizons of remaining UI eligibility and alternative labor market states.

\subsection{CARES Act specific formulation}

The temporary nature of the supplemental PUC income relative to the duration of payments of baseline UI requires a small modification to the unemployment Bellman equations above. Let $t_{c}$ denote the weeks of expanded UI eligibility, and $t_{p}$ the weeks of supplemental UI income under the PUC, remaining for a given unemployment spell. For simplicity it is assumed that $t_{p}<t_{c}$ for all unemployed. In addition, let $\bar{b}$ denote baseline UI payments and the additional income provided through the PUC by $b_{p}$. The value of unemployment under the CARES Act is:

$$
\begin{aligned}
W_{U}\left(\bar{b}, t_{c}, b_{p}, t_{p}\right)= & \bar{b}+b_{p}+\frac{1}{1+r}\left[(1-f) W_{U}\left(\bar{b}, t_{c}-1, b_{p}, t_{p}-1\right)\right. \\
& \left.+f \max \left[W_{E}(w), W_{U}\left(\bar{b}, t_{c}-1, b_{p}, t_{p}-1\right)\right]\right] \text { for } t_{c}, t_{p}>1 \\
W_{E}(w)= & w+\frac{1}{1+r}\left[(1-s) W_{E}(w)+s W_{U}\left(\bar{b}, T_{c}\right)\right]
\end{aligned}
$$

Following similar steps as in the previous section, the value of unemployment under the CARES Act with $t_{c}$ weeks of regular UI payments and $t_{p}$ weeks of PUC payments may be expressed as:

$$
W_{U}\left(\bar{b}, t_{c}, b_{p}, t_{p}\right)=\bar{B}\left(t_{c}\right)+B_{p}\left(t_{p}\right)+\frac{f}{r+r} W_{E}(w)
$$

where $\bar{B}(t)=\sum_{i=0}^{t-1} \bar{b}\left(\frac{1-f}{1+r}\right)^{i}$ and $B_{p}(t)=\sum_{i=0}^{t-1} b_{p}\left(\frac{1-f}{1+r}\right)^{i}$.

The level of supplemental UI payments leading to indifference to job offers at the previous wage $w$ with 1 and $t$ weeks remaining in PUC payments, respectively, are given by:

$$
\begin{aligned}
b_{p}^{r}\left(1, t_{c}, w\right) & =\frac{r}{r+f} W_{E}(w)-\bar{B}\left(t_{c}\right) \\
b_{p}^{r}\left(t, t_{c}, w\right) & =\frac{b_{p}^{r}\left(1, t_{c}, w\right)}{\sum_{i=0}^{t-1}\left(\frac{1-f}{1+r}\right)^{i}}
\end{aligned}
$$

The level of the supplemental benefit leading to indifference to job offers depends on the wage offer, the number of weeks of supplemental UI payments remaining, and the number of weeks of 
regular benefit payments remaining, $t_{c}$.

The reservation benefits during the pandemic calculated below is the sum of regular and supplemental reservation benefit payments, $b^{r}\left(t, t_{c}, w\right)=\bar{b}+b_{p}^{r}\left(t, t_{c}, w\right)$, with the following further assumptions. A baseline UI program, outside the additional provision under the CARES Act, is specified as a weekly payment $\bar{b}=\min \left[\bar{\tau} \times w, b_{\text {cap }}\right]$ for a maximum duration of $\bar{T}=26$ weeks, where $\bar{\tau} \in(0,1)$ is a replacement rate set to 50 percent and $b_{\text {cap }}$ a cap on weekly payments of $\$ 500 .{ }^{9}$ The PEUC extended the duration of UI payments an additional 13 weeks for a total of 39 weeks, but in some states emergency extensions provide an additional 13 weeks for a maximum of 52 weeks. $T^{c}$ is set to 52 weeks. The additional income provided through the PUC is denoted by $b_{p}=\$ 600$ per week. Payments first began the week ending April 4, 2020 and the last week ending July 25, 2020, for a total of $T_{p}=17$ weeks. Finally, the CARES Act provision of additional UI income is assumed to no longer be available at the end of the employment spell of any job offer under consideration. ${ }^{10}$

\subsection{Data - calculating reservation benefits}

The moments required to calculate reservation benefits are obtained from the monthly CPS. Table 1 reports mean and median weekly earnings, and several measures of expected unemployment and employment spell duration implied by job arrival and separation rates ( $f$ and $s$ ) for the overall population, prime aged workers, by level of education, and occupation. Weekly earnings are based on the full calendar year 2019, while measures of duration in the baseline exercise are drawn from the early recovery phase following the Great Recession (the full calendar year 2010). This period is chosen as a reasonable reference point for individuals unemployed during this period's expectations of job offer arrival rates coming out of the initial phase of the COVID-19 recession. The arrival rate $f_{t}=U E_{t} / U_{t-1}$ is the sum of transitions from unemployment to employment over the previous period's stock of unemployed individuals. The separation rate $s_{t}=\left(E U_{t}+E N_{t}\right) / E_{t-1}$ is the sum of transitions out of employment into either unemployment or non-employment over the preceding period's stock of employed individuals. Note that durations of unemployment spells based on outflow rates are significantly shorter than the average durations reported by CPS respondents. ${ }^{11}$

Transitions in and out of employment are not easily defined from responses to labor market status questions in the CPS for certain categories of workers or jobs. This applies to the transition rate $f$ by occupation, and the approach here is to estimate a logit on the outcome of a transition

\footnotetext{
${ }^{9}$ This assumption for regular UI compensation is slightly more generous than the typical U.S. state program. See Department of Labor (2019) for a review of the heterogeneity in eligibility requirements and benefit levels and duration across US states. Note also the discount rate $r$ is set to an annualized rate of $5 \%$.

${ }^{10}$ Allowing for the additional UI income to be available upon reemployment, at least partially, would increase the value of a job offer. The levels of the reservation benefit would be somewhat higher due to strong discounting over the duration of a typical employment spell.

${ }^{11}$ Table A1 provides durations of unemployment spells as self-reported in the CPS for comparison to the durations implied by the finding rate $f$. In particular, it reports the average duration of the unemployment spell preceding a transition into employment, which can be compared to the imputed finding rate based on durations by occupation. Table A3 of the appendix reports the equivalent moments for 2019. See also the discussion in Farber and Valletta (2015).
} 
from unemployment into employment, $f=\exp \left(\beta_{f} X\right) /\left[1+\exp \left(\beta_{f} X\right)\right]$, based on a set of demographic characteristics in the vector $X$ that includes age, education, race/ethnicity, sex and marital status. The regressions, using all months of 2010, are then used to predict the average transition rate by occupation. (see appendix B for further details).

\subsection{Results: Overall, by education and by occupation}

The discussion focuses on reservation benefit levels, and the corresponding replacements rates, for individuals with either 12 or 8 weeks of UI eligibility remaining. With the PUC benefit expiring July 31st 2020, this corresponds to individuals considering an offer to return to work at the previous wage in the first weeks of May and June 2020, respectively.

An typical worker, earning about $\$ 1000$ per week, received $\$ 1100$ per week in UI payments under the CARES act, or $110 \%$ of prior earnings. Considering an offer at the previous wage takes into account that the proposed employment spell is expected to last just under two years and, if rejected, unemployment can be expected to last 22 weeks (see the first row of Table 1). An offer during the first week of May 2020 would be accepted as long a the average worker's reservation benefit was below $b^{r}(12)=\$ 1,550$. This is $\$ 450$ above weekly UI payments under the CARES Act. In this case, the reservation benefit is $155 \%$ of the previous wage: a UI replacement rate of at least that amount is needed to cause this worker to reject the job offer, due to the temporary duration of UI payments compared with the possibility of a long employment spell. An offer during the first week of June, with 8 weeks of PUC payments remaining, is all the more attractive, raising the reservation benefit further. These conclusions are similar when the analysis is restricted to the prime age workforce, aged 25 to 54 years old (see the second row of Table 1).

The next three rows of Table 1 present the results for workers with three levels of education (less than high school, high school, and college and above). The additional payments under the CARES Act should not affect the job acceptance decisions of college educated workers: their employment spells have long durations (3 years) and pay earnings well above augmented UI payments. High school educated workers have earnings close to the national median at $\$ 800$ per week and expected durations of employment and job-finding rates close to the overall average. A $124 \%$ replacement rate under the CARES Act is well below the reservation benefit at the previous wage in early May (155\%) and even further below it in June 2020. Overall, based on the quantitative elements we used to calculate reservation benefit levels, only individuals with less than a high school education were likely to decline job offers due to enhanced UI payments when considering whether to accept a job offer in May 2020. However, even for this group, a job offer in June 2020, when many states were moving to reopen their economies, would have been preferable to remaining unemployed. 
Table 1: Reservation benefits and replacement rates

\begin{tabular}{|c|c|c|c|c|c|c|c|c|c|c|c|}
\hline & \multirow{2}{*}{$\begin{array}{r}\text { Earnings } \\
w \text { (wkly) }\end{array}$} & \multicolumn{2}{|c|}{ Duration of: } & \multicolumn{4}{|c|}{ Weekly UI compensation } & \multicolumn{4}{|c|}{ Replacement rates (\%) } \\
\hline & & $U$ (wks) & $E(\mathrm{yrs})$ & $\bar{b}$ & $b^{C}$ & $b^{r}(12)$ & $b^{r}(8)$ & $\bar{\tau}$ & $\tau^{C}$ & $\tau^{r}(12)$ & $\tau^{r}(8)$ \\
\hline Overall & 1007 & 22 & 1.7 & 500 & 1100 & 1553 & 1995 & 50 & 109 & 154 & 198 \\
\hline Age 25 to 54 years & 1087 & 21 & 2.3 & 500 & 1100 & 1732 & 2234 & 46 & 101 & 159 & 206 \\
\hline \multicolumn{12}{|l|}{ Education: } \\
\hline Less then HS & 513 & 23 & 0.74 & 256 & 856 & 708 & 907 & 50 & 167 & 138 & 177 \\
\hline High School & 807 & 22 & 1.6 & 403 & 1003 & 1246 & 1602 & 50 & 124 & 155 & 199 \\
\hline College and above & 1389 & 19 & 2.8 & 500 & 1100 & 2226 & 2884 & 36 & 79 & 160 & 208 \\
\hline \multicolumn{12}{|l|}{ Occupation: } \\
\hline Food Service & 464 & 21 & 1.1 & 232 & 832 & 670 & 856 & 50 & 179 & 144 & 184 \\
\hline Janitors & 549 & 22 & 0.9 & 274 & 874 & 780 & 999 & 50 & 159 & 142 & 182 \\
\hline Medical Assi. & 709 & 23 & 1.9 & 354 & 954 & 1139 & 1474 & 50 & 135 & 161 & 208 \\
\hline Sales and Retail & 873 & 21 & 1.6 & 436 & 1036 & 1313 & 1679 & 50 & 119 & 150 & 192 \\
\hline Transportation & 887 & 21 & 1.6 & 444 & 1044 & 1354 & 1737 & 50 & 118 & 153 & 196 \\
\hline Construction & 1000 & 20 & 0.9 & 500 & 1100 & 1339 & 1668 & 50 & 110 & 134 & 169 \\
\hline Teachers & 1090 & 19 & 1.9 & 500 & 1100 & 1632 & 2083 & 46 & 101 & 150 & 191 \\
\hline Nurses and therap. & 1203 & 21 & 3.4 & 500 & 1100 & 2010 & 2614 & 42 & 91 & 167 & 217 \\
\hline IT & 1466 & 19 & 4.5 & 500 & 1100 & 2404 & 3116 & 34 & 75 & 164 & 213 \\
\hline Managers & 1554 & 20 & 3.2 & 500 & 1100 & 2589 & 3381 & 32 & 71 & 166 & 218 \\
\hline
\end{tabular}

Notes: Earnings data calculated using the Dec. 2018 to Dec. 2019 CPS. Durations calculated using Dec. 2009 to Dec. 2010 CPS. $w$ : weekly earnings; Weekly job finding and separation rates entering the resevation benefits are obtained by converting the monthly flow rates to a weekly frequency (see appendix for details); $\bar{b}$ : regular weekly unempmloyment benefits; $b^{C}$ : weekly benefits under CARES act, $\bar{b}+600 \$$. 
The last rows of Table 1 present results for 10 major occupations. Weekly earnings in 2019 range from under $\$ 500$ a week (Food services) to over $\$ 1550$ a week (Managers), with average durations of employment spells from under a year (janitors and construction) to over three years (managers, nurses and therapists). The reservation benefits levels with 12 and 8 weeks remaining in PUC payments for each occupation are summarized in Figure 1, which plots an occupation's weekly earnings against reservation benefits. A 100\% replacement rate (black line) separates the graph in two regions, shaded in blue for replacement rates below $100 \%$. Regular UI payment rates are represented by the bottom line (red), increasing at a rate of $50 \%$ of the prior wage until hitting a cap at $\$ 1000$ in weekly earnings for a maximum benefit payment of $\$ 500$ per week. The UI payment schedule under the CARES Act is shifted up by $\$ 600$ (green line), and any individual with earnings below $\$ 1100$ per week receives more on UI with the PUC payments than on the previous job. Each occupation's weekly earnings and reservation benefit level with 12 and 8 weeks of PUC supplemental payments remaining are plotted as yellow and blue dots, respectively. At the time several states moved to reopen their economies, only insured unemployed workers who had been in food services were close to indifferent toward returning to work at their previous wage.

Figure 2 reports the same information but focuses on replacement rates explicitly. Under the CARES Act, all but three occupations out of ten have a replacement rate above $100 \%$. From the perspective of the first week of June, the vast majority of occupations show sizable gaps between their replacement rates with PUC payments and replacement rates that would cause UI recipients to be indifferent to a job offer at the previous wage. The exceptions are individuals employed in food services and janitors. For these two occupations, which comprise about $15 \%$ of the unemployed in May and June of 2020, UI payments under the CARES Act are close to their respective reservation benefit levels. ${ }^{12}$

In order to provide bounds for the values of reservation benefits under varying expectations for labor market conditions, the same calculations are performed under an alternative assumption for job offer arrival rates and durations of employment spells. This alternative uses the data from 2019 to obtain transition rates and would represent a situation in which the unemployed, when considering a job offer, expect a strong labor market rebound with far less difficulty finding a job. The result of increasing the arrival rate of job offers by about $50 \%$, as reported in Table A3, is to lower the level of reservation benefits in all occupations such that two of them, food services and janitors, would prefer remaining unemployed and receiving enhanced UI benefits to accepting a job at their previous wage during the first week of June 2020. This example is based on a scenario for the labor market that was not likely to be in the modal expectation of unemployed individuals and is meant to provide bounds on possible levels of reservation benefits during the period of increased UI payments under the CARES Act.

\footnotetext{
${ }^{12}$ We calculate the occupation shares among the unemployed restricting the population to individuals in the CPS aged 25 to 54 years old who report a prior occupation, excluding both job leavers and new entrants who would not be eligible for UI.
} 


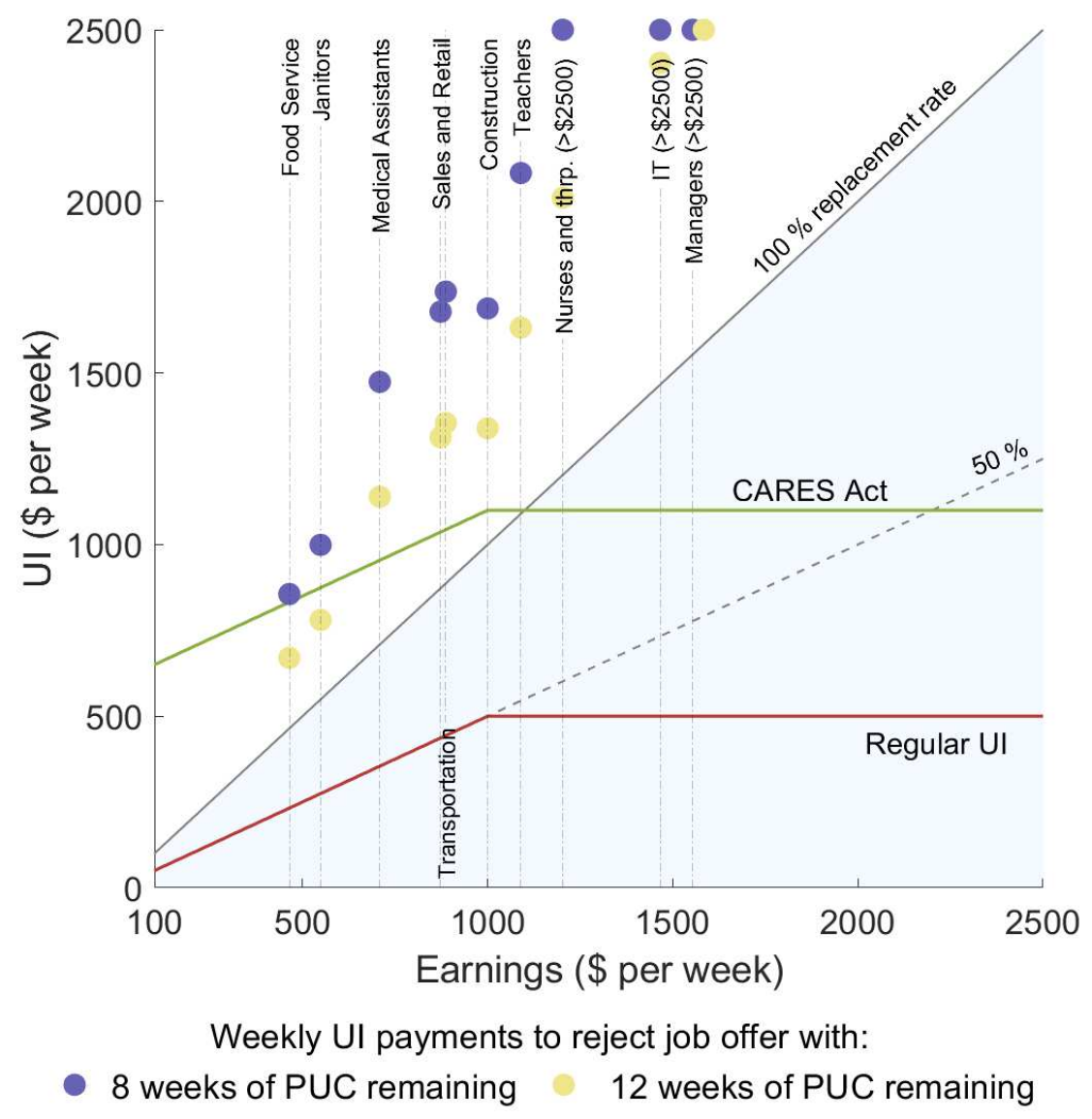

Figure 1: Regular, CARES Act and reservation level UI benefit payments Notes: Each dot corresponds to the reservation benefit for an average worker within each occupation calculated according to (12) with 12 (first week of May 2020) or 8 (first week of June 2020) weeks of PUC payments remaining. 


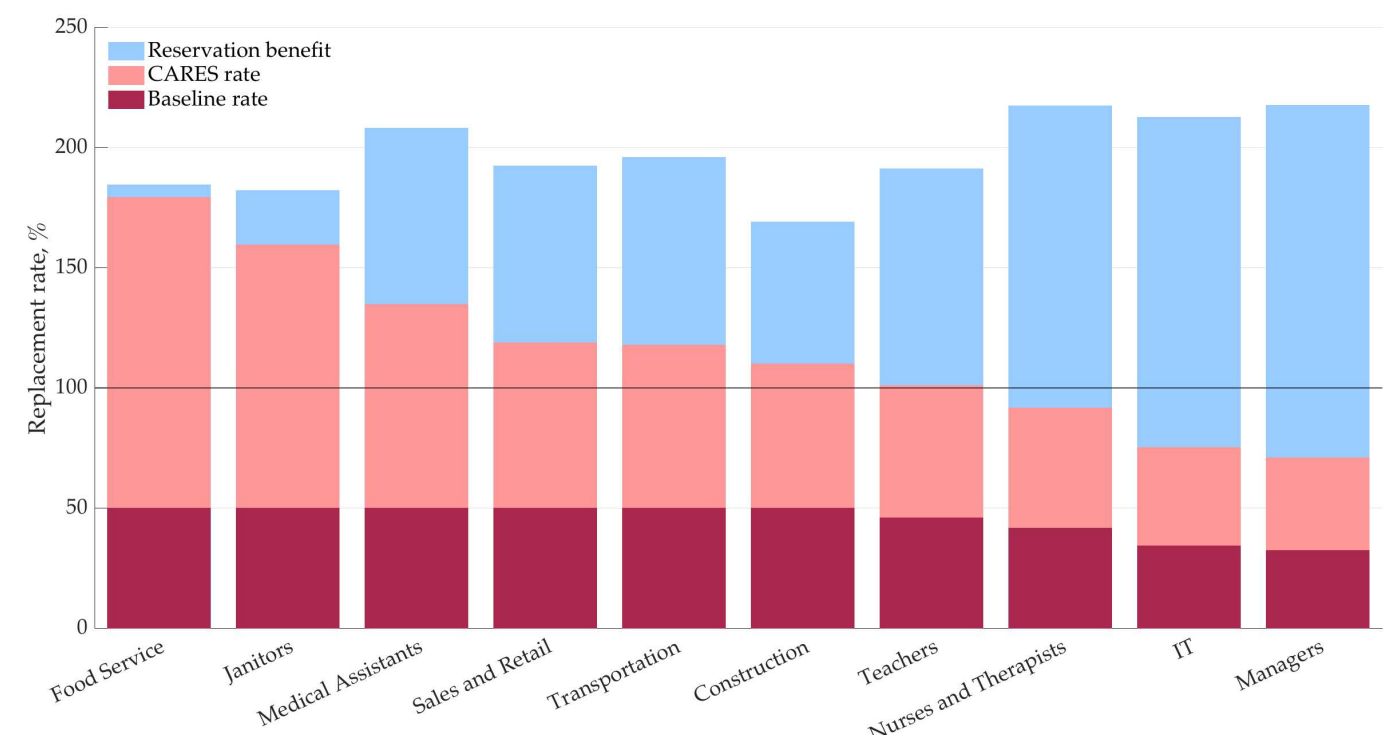

Figure 2: Regular, CARES Act and reservation level UI benefit replacement rates

Notes: The figures reports reservation benefit replacement rates with 8 weeks (first week of June 2020) remaining to the PUC program.

\subsection{State level estimates}

Regular UI benefit payments vary substantially across states, and by extension with the supplemental PUC payments. Regular weekly UI payments in Alabama were capped at \$275 compared with $\$ 790$ in Washington State in 2019, for example (Department of Labor 2019). This section calculates reservation benefits by state.

Reservation replacement rates with 8 weeks of PUC payments remaining for all 50 states are calculated following the same approach as earlier and mapped in Figure $3 a .{ }^{13}$ The map separates states in reservation replacement rate quintiles. The reservation replacement rates with 8 weeks of PUC payments remaining range from $134 \%$ of the previous wage in North Dakota to $247 \%$ in Massachusetts. North Dakota's lower reservation replacement rate is a result of the state's dynamic labor market with very short durations of unemployment spells. The typical unemployment spell in North Dakota in 2010 was expected to last 10 weeks. The elevated reservation replacement rate in Massachusetts is largely explained by significantly longer expected durations of job search, around 28 weeks.

This contrasts with actual replacement rates under the CARES Act for the average earner in the two states that are relatively similar: $111 \%$ in North Dakota and 102\% in Massachusetts (weekly state UI benefits were calculated adapting Ganong, Noel and Vavra (2020)'s UI calculator). The gap between CARES replacement and reservation replacement rates in North Dakota is relatively small but not negligible: 22 percentage points. The margin in Massachusetts, 145 percentage points, is quite wide. The large difference in reservation replacement rates and gaps with state

\footnotetext{
${ }^{13}$ The full set of state average earnings, job finding and separation rates, and results are available in appendix Table A4.
} 


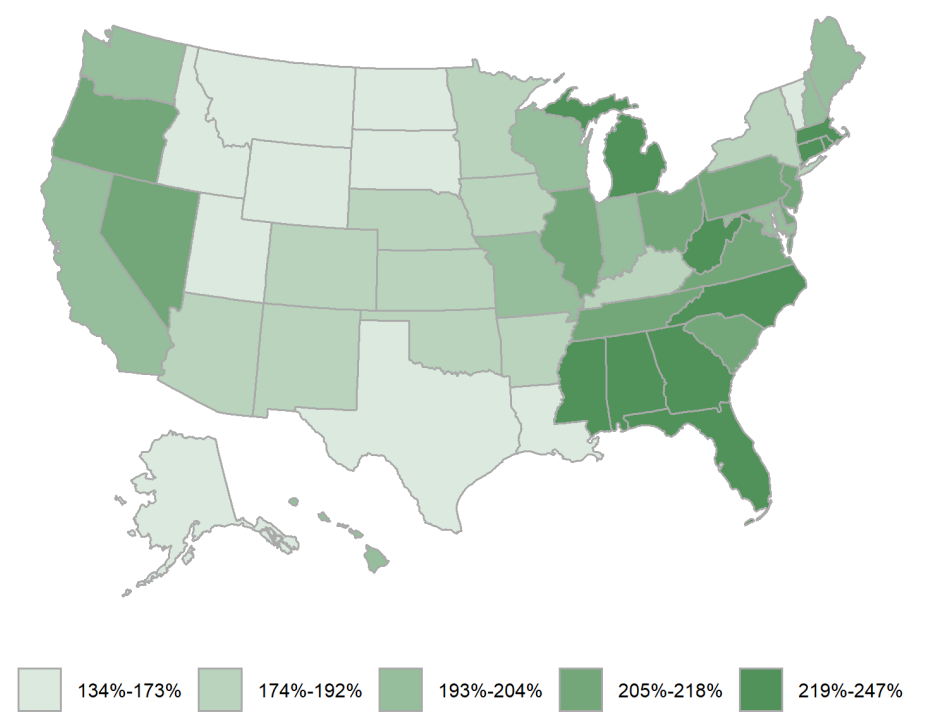

(a) Reservation replacement rates

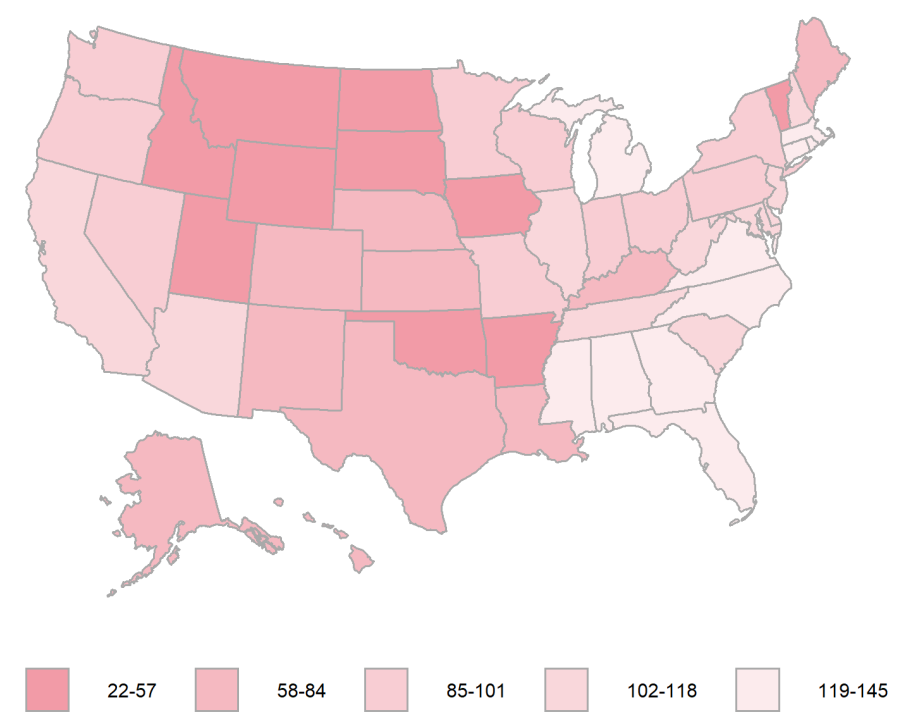

(b) Percent point gap between CARES and reservation replacement rates

Figure 3: State level CARES and reservation replacement rates with 8 weeks of PUC payments remaining

Notes: weekly earnings calculated from the monthly CPS, weekly state UI benefits calculated adapting Ganong, Noel and Vavra (2020)'s UI calculator. See appendix B for further details. 
UI under the CARES Act across the two states suggests the potential impacts of the supplemental PUC payments on job acceptance decisions should differ significantly. Figure $3 \mathrm{~b}$ maps quintiles of the percentage point gaps between CARES replacement rates and reservation replacements rates for all 50 states. Bartik et al. (2020) find that the pick up in the labor market during the initial attempts at reopening was strongest among the states with the highest UI benefit replacement rates. The analysis here shows these states also tended to have the largest gaps between the reservation benefit replacement rates and UI replacement rates under the CARES Act (light pink states in Figure $3 b$ ). These are states where the generous supplemental PUC payments would have been the least likely to distort job acceptance decisions (see, for example, Florida, Georgia, and North Carolina).

\section{CARES UI expansion and labor market transitions}

The analysis from preceding sections suggests that only a small fraction of job searchers were likely to reject job offers in favor of remaining unemployed and receiving UI benefits that include the $\$ 600$ / week CARES Act supplemental payments during early 2020. In this section, we conduct direct empirical tests to assess the extent to which the $\$ 600$ supplemental payments affected job finding rates and other labor market flows.

We implement a difference-in-differences regression framework to assess whether the change in job-finding rates and other labor market transitions between the pre-CARES and CARES periods is larger for individuals who receive the largest UI replacement rates due to the supplemental payments. ${ }^{14}$ Our value added relative to prior analyses of the potential disincentive effects of the supplemental payments arises from two specific features of our analyses: (i) we exploit individual variation in UI replacement rates; (ii) we directly assess the labor market transitions, in particular job-finding rates (exits from unemployment to employment), that may be affected by the moral hazard effect of UI benefit generosity. ${ }^{15}$

Our regression analyses rely on labor market transition data formed using data on individuals matched across consecutive monthly CPS files. We use data for early- to mid-2020 only, to focus on the impact of the extra $\$ 600 /$ week of UI payments specified by the CARES Act and available from late March through the end of July. We combine the monthly CPS data with estimated UI replacement rates that rely on our implementation of the calculator developed by Ganong, Noel and Vavra (2020) and annual earnings data from the CPS Annual Demographic Supplement for the individuals observed in our matched monthly CPS data. We discuss these steps in detail in the next two sub-sections.

\footnotetext{
${ }^{14}$ Because normal UI payments generally are determined as a fraction of prior earnings, the uniform $\$ 600$ supplement increased replacement rates more for individuals with low versus high prior earnings.

${ }^{15}$ By comparison, Bartik et al. (2020) rely on state-level variation in median replacement rates and employment/hours, and Altonji et al. (2020) and Finamor and Scott (2021) examine labor market status but not flows between labor market states. These papers reported little or no disincentive effects of the enhanced UI payment generosity on employment status. By contrast, Marinescu, Skandalis and Zhao (2021) examined job applications in local labor markets and found moderate reductions in application rates in areas with greater increases in UI benefit amounts.
} 


\subsection{Data I: Matched CPS data on labor market flows}

We use matched monthly data on individual labor force participants from the CPS (age 16-79). ${ }^{16}$ Because our empirical strategy requires linking monthly CPS files to annual earnings data from the CPS Annual Social and Economic Supplement (ASEC; see next sub-section), our observations are limited to the months of January through July of $2020 .{ }^{17}$

Due to the rotating sampling scheme used for the CPS, surveyed households and individuals are in the sample for two separate periods of 4 consecutive months (with an intervening 8-month period spent out of the sample). This enables consecutive month-to-month matching for about $70 \%$ of the sample. ${ }^{18}$ The monthly match is based on household identifiers and validated by ensuring that the reported data on age, education, race, and gender do not conflict across matched observations. We identify labor market transitions by comparing an individual's labor force status in consecutive months. We focus primarily on transitions out of unemployment (U), to employment $(\mathrm{E})$ or out of the labor force $(\mathrm{N})$, denoting them as UE or UN transitions respectively. Given relaxed job search requirements under the CARES Act UI expansions, we also examine out of the labor force to employment (NE) transitions.

A well-known concern regarding matched CPS data is the likelihood of spurious transitions in labor force status arising from inconsistent or error-ridden survey responses rather than meaningful changes (Abowd and Zellner 1985; Poterba and Summers 1986, 1995). Such spurious transitions could impart a downward bias to the estimated effects of UI payments on labor forced transitions and reduce the precision of the estimates. We therefore follow past research by adjusting the data to minimize the incidence of spurious transitions (Rothstein 2011, Valletta 2014, Farber and Valletta 2015, Farber, Rothstein and Valletta 2015). In particular, for individuals identified as leaving unemployment one month, either through job finding or labor force exit, and then returning to unemployment the next month, their records are recoded to show no transition (and the newly created observations are retained). We refer to these as "two-month matches," although the resulting transitions are still measured on a consecutive monthly basis. ${ }^{19}$ The results for unemployment exits reported below generally are based on these adjusted transitions, although we also provide some comparison to specifications that do not make this adjustment. In addition, we do not apply this adjustment to our analysis of transitions from out of labor force to employed (NE), because the measurement distortion generally applies to transitions in and out of unemployment.

\footnotetext{
${ }^{16}$ See Valletta (2014) for more details on construction of a similar sample for an earlier timeframe (in particular, Table 2 and the associated discussion in that paper).

${ }^{17}$ The ASEC is administered primarily in March, although some CPS respondents receive the supplement in other months. With the 4-month rotation in the monthly CPS, this enables us to use observations with ASEC information for the months of January through July of 2020.

${ }^{18}$ Most of the non-matched observations are from the "outgoing rotation groups" that are exiting the sample for eight months or permanently (one quarter of each monthly sample). In addition, a modest fraction of observations is lost because respondent households that move to different geographic locations are not followed.

${ }^{19}$ This adjustment requires restriction of the final analysis sample to individuals who are observed to be in their first or second month of a consecutive four-month span in the sample, thereby reducing the matched sample count by approximately one-third and eliminating July observations from our analyses. The adjustment reduces the incidence of transitions out of unemployment by about 5 percentage points on average.
} 


\subsection{Data II: UI Replacement rates}

Our analysis relies on UI replacement rates calculated at the individual level, defined as the ratio of weekly UI payments to weekly earnings prior to the job loss that resulted in the UI claim. As discussed in Ganong, Noel and Vavra (2020), UI replacement rates typically are slightly below 0.5 in the United States (50\% of prior earnings), absent benefit supplements. They calculate that the $\$ 600$ CARES Act UI supplement raised the typical replacement rate substantially, to 1.34, implying that the majority of UI recipients were eligible for UI payments that exceeded their prior weekly earnings. As part of their research, Ganong et al. constructed a calculator for replacement rates based on individuals' recent prior earnings history, which they have made publicly available. ${ }^{20}$

We use the Ganong et al. calculator to form estimated UI replacement rates for the individuals in our data. This requires individual employment and earnings data from prior quarters. We therefore restrict our matched monthly CPS sample to individuals who are included in the 2020 CPS ASEC sample. As noted above, this limits the sample to the months of January through July 2020. The ASEC includes information on weeks worked, hours, and earnings in the prior calendar year (2019 in this case, which largely contains the qualifying earnings period for potential UI recipients in our sample from early 2020). ${ }^{21}$ Because no information is provided on the timing of employment and earnings across the four quarters of the year, we spread them out evenly across all four quarters for the purposes of applying the UI benefits calculator. ${ }^{22}$

\subsection{Regression specification and results}

Using our matched monthly CPS data combined with UI replacement rates calculated as described above, we estimate regressions of the following form:

$$
\operatorname{Pr}\left(Y_{i t}=1\right)=\delta R_{i}+\left(\pi_{1,2,3,4} \times R_{i} \times(\text { Mar, Apr, May, Jun })\right)+\psi_{t}+\beta X_{i t}+\lambda Z_{s t}
$$

In this equation, the dependent variable $Y_{i t}$ is an indicator for whether an individual $i$ transitions between the specified labor market states across consecutive months (observed in month $t$, based on status in months $t$ and $t-1$ ). We focus primarily on transitions out of unemployment but also examine transitions from out of the labor force to employment (UE, UN, and NE transitions).

The key explanatory variables are the individual's UI replacement rate $\left(R_{i}\right)$ under the CARES Act and its interaction with indicators for the months of March through June (with estimated coefficients $\delta$ and $\pi_{1,2,3}$ ). The replacement rate varies across individuals but not over time and hence is not the key source of variation in this equation. Instead, the treatment effect of the $\$ 600$ CARES supplement is captured by the impact of the replacement rate after the CARES Act was

\footnotetext{
${ }^{20}$ https://github.com/PSLmodels/ui_calculator

${ }^{21}$ Ganong et al. used 2018 as their base earnings year. Our use of 2019 may introduce errors into our calculations of UI replacment rates, although the relevant changes in state UI eligibility rules likely were limited.

${ }^{22}$ The rules specifying which prior earnings quarters are used to determine UI eligibility and weekly payments vary across states.
} 
implemented and the supplemental payments were available, beginning in late March 2020, between the March and April CPS reference periods. These effects are estimated by the coefficients on the interactions between the replacement rate $R_{i}$ and indicators for the months of April-June, following a conventional difference-in-differences estimation approach with regression controls (and with the months of February and March used as baseline control periods).

The regression specification also includes controls for calendar month $\left(\psi_{t}\right)$. In addition, the vector $X_{i t}$ consists of individual-level controls: age (five categories), education (five categories), race/ethnicity (five categories), gender by marital status, broad industry of prior employment (14 categories), and duration to date of the individual's unemployment spell (10 categories, with the final category indicating duration of longer than one year). ${ }^{23}$ The model also includes several state/month labor market controls $\left(Z_{s t}\right)$ : cubics in the state unemployment rate and three-month employment growth rate.

Estimation is via a logit model, with reported parameter estimates converted into average marginal effects. All estimates are weighted by the CPS labor force weights, and robust standard errors are provided. ${ }^{24}$ The underlying sample contains observations for the months of January through July of 2020, although the estimation samples generally are restricted to the months of February through June for the reasons described above. We restrict the analysis to individuals with non-zero estimated UI replacement rates under the CARES Act-i.e., individuals who are identified as eligible to receive UI payments based on their prior earnings history-to avoid distorting the results via unobservable differences between UI eligible and ineligible individuals.

\subsubsection{Results}

The results for unemployment exits and other labor force transitions are displayed in Table 2. The preferred specification for unemployment exits, which uses the two-month match that corrects for temporary exits from unemployment, is reported in the first column. ${ }^{25}$ The results show generally negative effects of UI benefit generosity on job finding: exit rates during the months of April through June are lower for individuals whose post-CARES UI replacement rates rise the most. ${ }^{26}$ This effect is statistically significant at conventional levels (5\%) for the month of May but only marginally significant for the months of April and June. The fragility of these estimates suggests that the disincentive effects of enhanced UI generosity on job search only affects a small fraction of the sample, consistent with the calculations presented earlier in this paper. We discuss the magnitude of the estimated effects further below.

\footnotetext{
${ }^{23}$ For regressions in which the initial state is out of the labor force, the unemployment duration and industry variables are excluded.

${ }^{24}$ The regression results are very similar when the CPS longitudinal weights are used.

${ }^{25}$ The two-month match requires at least three consecutive monthly observations; see the discussion of the third column below for a further restriction to four consecutive monthly observations (balanced sample).

${ }^{26}$ The pre-CARES (February and March) exit rates are somewhat higher for individuals with the highest UI replacement rates under the CARES Act enhancements. This likely reflects systematic unobserved differences between individuals with high and low replacement rates, for example high replacement rate individuals working in low-wage labor markets with high turnover and job-finding rates. This baseline difference is not evident in subsequent columns.
} 
Table 2: Regression results:: UI replacement rates and labor force transitions

\begin{tabular}{cccccc}
\hline & $\begin{array}{c}(1) \\
\text { UE (2-month } \\
\text { match) }\end{array}$ & $\begin{array}{c}(2) \\
\text { UE (1-month } \\
\text { match) }\end{array}$ & $\begin{array}{c}(3) \\
\text { UE(2-month, } \\
\text { balanced sample) }\end{array}$ & $\begin{array}{c}(4) \\
\text { UN (2-month } \\
\text { match) }\end{array}$ & $\begin{array}{c}\text { NE (1-month } \\
\text { match) }\end{array}$ \\
\cline { 2 - 6 } UI rep rate & $0.056^{*}$ & 0.022 & 0.097 & 0.011 & 0.002 \\
UI rep*Mar & $(0.033)$ & $(0.027)$ & $(0.059)$ & $(0.016)$ & $(0.010)$ \\
& -0.009 & 0.0015 & -0.038 & -0.029 & -0.003 \\
UI rep*Apr & $(0.043)$ & $(0.037)$ & $(0.066)$ & $(0.038)$ & $(0.013)$ \\
& $-0.083^{*}$ & -0.020 & -0.108 & 0.004 & -0.007 \\
UI rep*May & $(0.044)$ & $(0.034)$ & $(0.066)$ & $(0.018)$ & $(0.017)$ \\
& $-0.082^{* *}$ & -0.048 & $-0.115^{*}$ & 0.009 & -0.020 \\
UI rep*June & $(0.038)$ & $(0.030)$ & $(0.061)$ & $(0.017)$ & $(0.014)$ \\
& -0.073 & $-0.065^{* *}$ & -0.100 & 0.015 & -0.020 \\
UI rep*July & $(0.047)$ & $(0.033)$ & $(0.067)$ & $(0.030)$ & $(0.019)$ \\
Observations & - & -0.006 & - & - & 0.011 \\
& 2769 & $(0.047)$ & & & $(0.038)$ \\
\hline pr.10, & 5441 & 2564 & 2782 & 6945 \\
\hline
\end{tabular}

${ }^{*} \mathrm{p}<.10,{ }^{* *} \mathrm{p}<.05,{ }^{* * *} \mathrm{p}<.01$

Notes: Logit regression model results (average marginal effects and robust standard errors) from matched CPS microdata, Jan.-Jul. 2020, combined with 2020 CPS ASEC data to form individual UI replacment rates (including \$600 supplement from CARES Act). Regressions controls include: age (five categories), education (five categories), race/ethnicity (five categories), gender by marital status, broad industry of prior employment (14 categories), duration to date of the individual's unemployment spell (10 categories, with the final category indicating duration of longer than one year); state/month economic conditions (cubics in the unemployment rate and employment growth); and a vector of calendar month dummies. The duration and industry controls are excluded from column 5. 
The second and third columns of the table show results from selected robustness checks. The second column shows results for the same specification as in the first column, but with the twomonth match restriction removed, so that all consecutive monthly transitions are included and no correction is made for reported temporary exits from unemployment. As expected given the greater noise in the measured transition rates, the estimated coefficients are reduced in size and significance, with only the June interaction effect remaining significant (despite the reduced standard errors afforded by the larger sample size compared with the first column). The third column is comparable to column 1 but with the sample shrunk slightly via restriction to individuals who are present for four consecutive months. This increases the magnitude of the estimated coefficients somewhat but reduces their precision.

We also examined whether UI generosity affects exits from unemployment to out of labor force (UN), with the results displayed in column 4 of the table. This follows earlier empirical results suggesting that UI benefits may increase labor force attachment, because active job search generally is a requirement for UI eligibility in the United States (e.g., Farber, Rothstein and Valletta 2015, Card, Chetty and Weber 2007). The results in column 4 show no effect of UI replacement rates on reported labor force exits (from unemployment). This contrasts with the earlier empirical findings of enhanced labor force attachment due to extended UI durations, likely because the job search requirements for UI eligibility were relaxed during the initial phase of the COVID-19 pandemic in the first half of 2020. Finally, column 5 presents results for job-finding rates from out of the labor force (NE); the results provide no evidence that these transition rates were affected by the increase in UI generosity due to the CARES Act.

We assess the magnitude of the estimated impact of the CARES supplement based on the results from our preferred specification for unemployment exit rates in the first column. Given the wide span of post-CARES UI replacement rates observed in our data, various metrics could be used to interpret the size of the estimated effect. ${ }^{27}$ Interpretation of the coefficients is straightforward, however: the replacement rate is measured relative to a value of 1.0 (UI payments equal to prior earnings), and the coefficients are average marginal effects, so the month interactions represent the effect of an increase in the UI replacement rate of 1 (100 percentage points) on the probability of observing the relevant transition rate.

We conduct a straightforward calculation based on these considerations. The $\$ 600 /$ week additional payments raised the median replacement rate from 0.5 to 1.36 in our sample of unemployed individuals (with two-month matches). ${ }^{28}$ This represents an increase in the typical replacement rate of 0.86 . Combined with the coefficients on the month interactions in column 1 of the table, this implies for example that in the month of May the job-finding rate for the typical individual in our sample was reduced by about 7.1 percentage points. ${ }^{29}$ This is of moderate size relative

\footnotetext{
${ }^{27}$ As noted earlier, the $\$ 600$ supplement substantially raised the typical replacement rates. It also widened the dispersion substantially, with the standard deviation of replacement rates across UI-eligible individuals rising by nearly a factor of seven.

${ }^{28}$ The post-CARES median replacement rate of 1.36 in our sample is very close to the Ganong et al. (2020) calculation of 1.34 , with a small difference attributable to our different sample restrictions.

${ }^{29}$ The specific calculation is $0.86^{*}(-0.082)=-0.071$.
} 


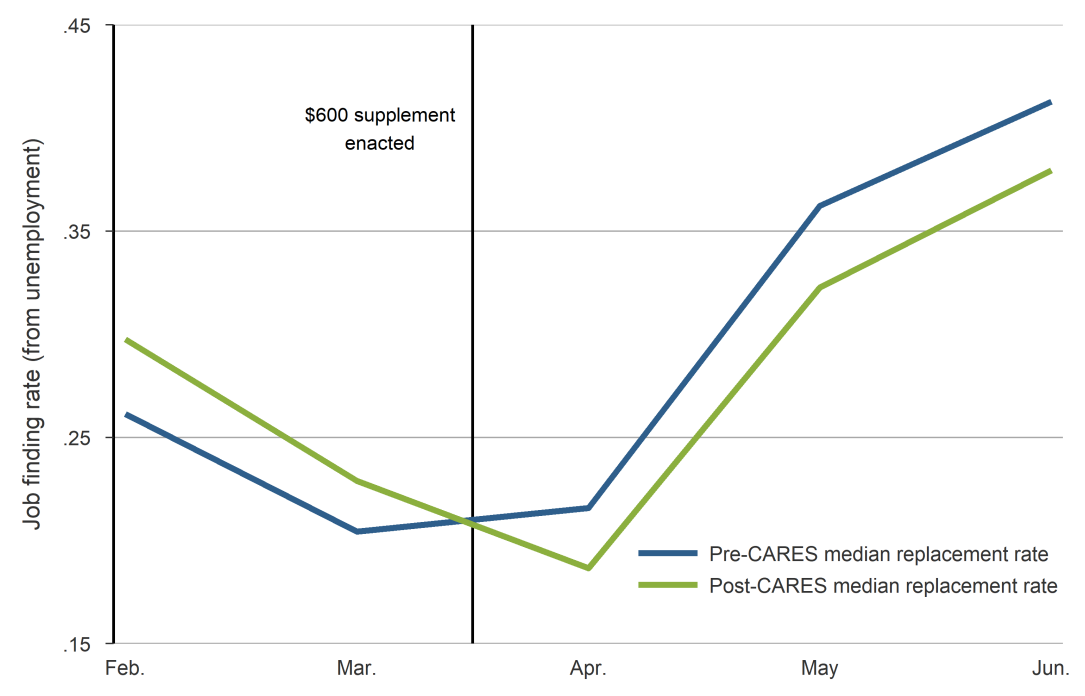

Figure 4: Job finding rates (from unemployment), by UI replacement rates (pre/post CARES Act) Notes: Logit regression results using matched CPS microdata, Jan.-Jul. 2020, linked to CPS ASEC to form UI replacement rates based on 2019 earnings. Flows corrected for reported transitions out of unemployment followed by a return to unemployment in the next month. Additional regression controls include individual and job characteristics, state labor market conditions, and time effects.

to an overall job-finding rate of just under 35 percentage points $(0.35)$ in that month. As noted above, however, given the statistical fragility of the estimates, this likely reflects a large disincentive effect for a small fraction of the sample. Moreoever, these direct estimates of small reductions in job-finding rates due to the $\$ 600$ supplement are consistent with the calculations in preceding sections regarding the small but meaningful share of job seekers who would choose to remain unemployed and receive UI rather than accepting job offers, based on their estimated reservation benefit levels.

Figure 4 shows the time pattern of UI generosity effects on job-finding rates based on the column 1 results from Table 2, using the median increase in replacement rates of 0.86 noted above and comparing exit rates for individuals at those two levels of replacement rates. A drop in relative job-finding rates for those with higher replacement rates is evident in April. In subsequent months, job-finding rates increase for both groups, but the job-finding rates for those with higher post-CARES replacement rates remain somewhat lower than for those with lower replacement rates.

\subsubsection{Discussion, including implications for 2021}

Our results show moderate and imprecisely estimated disincentive effects of the very large increase in UI replacement rates created by the $\$ 600$ weekly UI supplemental payments implemented by the CARES Act in late March 2020. By contrast, earlier work found little or no disincentive effect of the enhanced UI payments on employment status (Altonji et al. 2020, Finamor and Scott 2021, Bartik et al. 2020). The differences in our results may reflect in part our narrower focus on 
individual replacement rates combined with direct measurement of job-finding rates, which are the primary outcome likely to be affected by the potential moral hazard effects of UI generosity. In addition, our focus on the effects measured narrowly at the individual level may enable us to capture the direct "micro" effects on individual search behavior, versus more general "macro" effects that may include additional consumption spending and hiring induced by the overall stimulus effects of UI payments (e.g., Gruber 1997, Boone et al. 2016).

It is also useful to consider the effects of increases in UI generosity due to the post-CARES Act relief packages. The CARES Act $\$ 600$ weekly UI suppplement expired in July 2020. Since late December 2020, a combination of federal acts have provided an additional $\$ 300$ per week in UI payments, with eligibility through September 6, 2021, for states that choose to maintain it. Based on a simple extrapolation of our regression framework, the \$300 weekly supplement in early 2021 reduces job-finding rates by about half as much as the $\$ 600$ supplement in early 2020. In particular, our estimates suggest that the $\$ 300$ supplement reduces monthly job-finding rates by a maximum of about 3.5 percentage points (0.035). For the first four months of 2021, job-finding (UE) rates have been averaging just under 0.25 per month. The estimated impact of the $\$ 300$ supplement, at 0.035 , is about one-seventh of that baseline job-finding rate. One straightforward way to think about that number is that each month in early 2021, about seven out of 28 unemployed individuals

receive job offers that they would normally accept, but one of the seven decides to decline the offer due to the availability of the extra $\$ 300$ per week in UI payments. This implies a small but likely noticeable contribution of expanded UI generosity to job-finding rates and employers' perceptions of worker availability in early 2021. This extension of our results from the 2020 CARES Act to early 2021 should be interpreted as preliminary and tentative because labor market conditions and key features of the UI provisions, notably their expected timeframe, are different between the two periods.

\section{Conclusion}

This paper derives a level of UI benefit payments over the duration of remaining UI eligibility at which workers are indifferent between a job at the previous wage and remaining unemployed. This reservation benefit reflects the value of forgoing a job offer compared to continued unemployment and, with finite benefit duration, is always above the previous wage. In a depressed labor market with lower job offer arrival rates, the gap between the previous wage and the reservation benefit widens, leaving room for replacement ratios above $100 \%$ without negative effects on job acceptance rates and resulting labor market adjustment. Our analyses using CPS micro data on weekly earnings, average durations of employment spells, and job finding rates show that limited types and shares of workers would refuse an offer to return to work at their previous pay even if they could receive three months of increased UI income under the CARES Act. A further direct empirical analysis of labor force transitions using matched CPS data, linked to annual earning records from the CPS income supplement to form UI replacement rates, shows moderate and 
imprecisely estimated disincentive effects of the UI supplemental payments on job finding rates. These direct estimates of small reductions in job-finding rates due to the $\$ 600$ supplement are consistent with our reservation benefit calculations showing that only a small share of job seekers would choose to remain unemployed and receive UI payments that include the supplement rather than accepting job offers. Moreover, a simple extrapolation of those empirical results to early 2021 suggests that the $\$ 300$ weekly UI supplement currently in place has been making a small but likely noticeable contribution to job-finding rates and employers' perceptions of worker availability.

It is worth noting a few considerations that may have a meaningful impact on an individual's job acceptance decision in the context of our model. First, there is no disutility to search / unemployment, nor additional utility while unemployed relative to working. Disutility from search would push job seekers to accept job offers and lower the level of reservation benefits. The additional utility from leisure would have the opposite effect. Second, the specification does not model the depreciation of skill or human capital or of other factors that would result in a declining in the job arrival rate over the duration of the unemployment spell. This consideration would act to increase the reservation benefit level, especially as individuals experience longer unemployment spells during a protracted slowdown. Finally, these are partial equilibrium exercises and do not take into account general equilibrium effects of expanding UI policies, which include supporting aggregate demand, on job offer arrival and separation rates. This is left to future work. 


\section{References}

Abowd, John, and Arnold Zellner. 1985. "Estimating Gross Labor Flows." Journal of Business and Economic Statistics, 3(3): 254-83.

Acemoglu, Daron. 2001. “Good Jobs versus Bad Jobs." Journal of Labor Economics, 19(1): 1-21.

Acemoglu, Daron, and Robert Shimer. 1999. "Efficient Unemployment Insurance." Journal of Political Economy, 107(5): 893-928.

Altonji, Joseph, Zara Contractor, Lucas Finamor, Ryan Haygood, Ilse Lindenlaub, Costas Meghir, Cormac O’Dea, Dana Scott, Liana Wang, and Ebonya Washington. 2020. "Employment Effects of Unemployment Insurance Generosity During the Pandemic." Yale University Manuscript.

Baily, Martin Neil. 1978. "Some aspects of optimal unemployment insurance." Journal of Public Economics, 10(3): 379 - 402.

Baker, Michael, and Samuel A. Rea. 1998. "Employment Spells and Unemployment Insurance Eligibility Requirements." The Review of Economics and Statistics, 80(1): 80-94.

Bartik, Alexander W., Marianne Bertrand, Feng Lin, Jesse Rothstein, and Matthew Unrath. 2020. "Measuring the labor market at the onset of the COVID-19 crisis." Brookings Papers on Economic Activity Conference draft.

Boar, Corina, and Simon Mongey. 2020. “Dynamic Trade-offs and Labor Supply Under the CARES Act." NBER Working Paper 27727.

Boone, Christopher, Arindrajit Dube, Lucas Goodman, and Ethan Kaplan. 2016. "Unemployment Insurance Generosity and Aggregate Employment." American Economic Journal: Economic Policy, forthcoming.

Burdett, Kenneth, and Bryce Hool. 1983. "Layoffs, wages and unemployment insurance." Journal of Public Economics, 21(3): 325 - 357.

Card, David, Raj Chetty, and Andrea Weber. 2007. "The Spike at Benefit Exhaustion: Leaving the Unemployment System or Starting a New Job?" American Economic Review, 97(2): 113-118.

Chetty, Raj. 2008. "Moral Hazard versus Liquidity and Optimal Unemployment Insurance." Journal of Political Economy, 116(2): 173-234.

Chodorow-Reich, Gabriel, John Coglianese, and Loukas Karabarbounis. 2019. "The Macro Effects of Unemployment Benefit Extensions: A Measurement Error Approach." Quarterly Journal of Economics, 134(1): 227-279. Replication folder.

Department of Labor. 2019. “Comparison of State Unemployment Laws 2019.” 
Farber, Henry S, and Robert G Valletta. 2015. "Do extended unemployment benefits lengthen unemployment spells? Evidence from recent cycles in the US labor market." Journal of Human Resources, 50(4): 873-909.

Farber, Henry S., Jesse Rothstein, and Robert G. Valletta. 2015. "The Effect of Extended Unemployment Insurance Benefits: Evidence from the 2012-2013 Phase-Out." American Economic Review, 105(5): 171-76.

Feldstein, Martin. 1976. "Temporary Layoffs in the Theory of Unemployment." Journal of Political Economy, 84(5): 937-57.

Finamor, Lucas, and Dana Scott. 2021. "Labor market trends and unemployment insurance generosity during the pandemic." Economics Letters, 199: 109722.

Ganong, Peter, Pascal J Noel, and Joseph S Vavra. 2020. “US Unemployment Insurance Replacement Rates During the Pandemic." National Bureau of Economic Research Working Paper 27216.

Gregory, Victoria, Guido Menzio, and David G Wiczer. 2020. "Pandemic Recession: L or VShaped?" National Bureau of Economic Research Working Paper 27105.

Gruber, Jonathan. 1997. “The Consumption Smoothing Benefits of Unemployment Insurance." The American Economic Review, 87(1): 192-205.

Hopenhayn, Hugo A., and Juan Pablo Nicolini. 2009. "Optimal Unemployment Insurance and Employment History." The Review of Economic Studies, 76(3): 1049-1070.

Kroft, Kory, and Matthew J. Notowidigdo. 2016. "Should Unemployment Insurance Vary with the Unemployment Rate? Theory and Evidence." The Review of Economic Studies, 83(3): 10921124.

Lalive, Rafael, Camille Landais, and Josef Zweimüller. 2015. “Market Externalities of Large Unemployment Insurance Extension Programs." American Economic Review, 105(12): 3564-96.

Marinescu, Ioana, and Daphné Skandalis. 2021. “Unemployment Insurance and Job Search Behavior." The Quarterly Journal of Economics, 136(2): 887-931.

Marinescu, Ioana Elena, Daphne Skandalis, and Daniel Zhao. 2021. "The Impact of the Federal Pandemic Unemployment Compensation on Job Search and Vacancy Creation." Social Science Research Network SSRN Scholarly Paper ID 3801802.

Moffitt, Robert. 1985. "Unemployment insurance and the distribution of unemployment spells." Journal of Econometrics, 28(1): 85-101. 
Poterba, James, and Lawrence Summers. 1995. "Unemployment Benefits and Labor Market Transitions: A Multinomial Logit Model with Errors in Classification." The Review of Economics and Statistics, 77(2): 207-16.

Poterba, James M., and Lawrence H. Summers. 1986. “Reporting Errors and Labor Market Dynamics." Econometrica, 54(6): 1319-1338.

Rothstein, Jesse. 2011. "Unemployment Insurance and Job Search in the Great Recession." Brookings Papers on Economic Activity, 42(2 (Fall)): 143-213.

Shimer, Robert, and Iván Werning. 2007. "Reservation Wages and Unemployment Insurance." The Quarterly Journal of Economics, 122(3): 1145-1185.

Valletta, Robert G. 2014. "Recent extensions of U.S. Unemployment benefits: Search responses in alternative labor market states." IZA Journal of Labor Policy, , (3): 1-25. 


\section{Online appendix}

\section{A Detailed derivations}

\section{A.1 Main derivations}

Recall the Bellman equations:

$$
\begin{aligned}
W_{E} & =w+\frac{1}{1+r}\left[(1-s) W_{E}+s W_{U}(b, T)\right] \\
W_{U}(b, t) & =b+\frac{1}{1+r}\left[(1-f) W_{U}(b, t-1)+f W_{E}\right] \text { for } T \geq t>1 \\
W_{U}(b, 1) & =b+\frac{1}{1+r}\left[(1-f) W_{U}(0)+f W_{E}\right] \\
W_{U}(0) & =0+\frac{1}{1+r}\left[(1-f) W_{U}(0)+f W_{E}\right]
\end{aligned}
$$

From the last line we have $W_{U}(0)=\frac{f}{r+f} W_{E}$, then:

$$
\begin{aligned}
W_{U}(b, 1) & =b+\frac{1}{1+r}\left[(1-f) \frac{f}{r+f} W_{E}+f W_{E}\right]=b+\frac{f}{r+f} W_{E} \\
W_{U}(b, 2) & =b+\frac{1}{1+r}\left[(1-f) W_{U}(b, 1)+f W_{E}\right] \\
& =b+b\left(\frac{1-f}{1+r}\right)+\frac{1}{1+r}\left[(1-f) \frac{f}{r+f}+f\right] W_{E} \\
& =b+b\left(\frac{1-f}{1+r}\right)+\frac{f}{r+f} W_{E}
\end{aligned}
$$

and finally:

$$
W_{U}(b, t)=\sum_{i=0}^{t-1} b\left(\frac{1-f}{1+r}\right)^{i}+\left(\frac{f}{r+f}\right) W_{E}
$$

Let $b^{r}(t, w)$ denote the value of unemployment benefit with $t$ weeks of eligibility remaining such that an individual is just indifferent between a job offer and remaining unemployed. With one week of benefits remaining:

$$
\begin{aligned}
W_{U}\left(b^{r}(1, w), 1\right) & =W_{E} \\
b^{r}(1, w)+\frac{f}{r+f} W_{E} & =W_{E} \\
b^{r}(1, w) & =\left(\frac{r}{r+f}\right) W_{E}
\end{aligned}
$$


With two weeks remaining:

$$
\begin{aligned}
W_{U}\left(b^{r}(2, w), 2\right) & =W_{E} \\
b^{r}(2, w)\left[1+\left(\frac{1-f}{1+r}\right)\right]+\frac{f}{r+f} W_{E} & =W_{E} \\
b^{r}(2, w) & =\frac{\left(\frac{r}{r+f}\right) W_{E}}{\left[1+\left(\frac{1-f}{1+r}\right)\right]}=\frac{b^{r}(1, w)}{\left[1+\left(\frac{1-f}{1+r}\right)\right]}
\end{aligned}
$$

such that $b^{r}(2, w)<b^{r}(1, w)$. More generally: for $T>t>1$

$$
b^{r}(t, w)=\frac{b^{r}(1, w)}{\sum_{i=0}^{t-1}\left(\frac{1-f}{1+r}\right)^{i}}
$$

Finally, we can re-express the value of employment as:

$$
\begin{aligned}
W_{E} & =\frac{w+\frac{s}{1+r} W_{U}(b, T)}{1-\left(\frac{1-s}{1+r}\right)} \\
W_{E} & =\left(\frac{1+r}{r+s}\right) w+\left(\frac{s}{r+s}\right) W_{U}(b, T)=\left(\frac{1+r}{r+s}\right) w+\left(\frac{s}{r+s}\right) B(T)+\left(\frac{s}{r+s}\right)\left(\frac{f}{r+f}\right) W_{E} \\
r W_{E} & =\frac{r+f}{r+f+s}[(1+r) w+s B(T)]
\end{aligned}
$$

such that

$$
b^{r}(1, w)=\frac{(1+r) w+s B(T)}{r+s+f}
$$

\section{A.2 Application to the 2020 CARES Act}

The value of unemployment under the CARES Act is:

$$
\begin{aligned}
W_{U}\left(\bar{b}, t_{c}, b_{p}, t_{p}\right)= & \bar{b}+b_{p}+\frac{1}{1+r}\left[(1-f) W_{U}\left(\bar{b}, t_{c}-1, b_{p}, t_{p}-1\right)\right. \\
& \left.+f \max \left[W_{E}(w), W_{U}\left(\bar{b}, t_{c}-1, b_{p}, t_{p}-1\right)\right]\right] \text { for } t_{c}, t_{p}>1 \\
W_{U}\left(\bar{b}, t_{c}, b_{p}, 1\right)= & \bar{b}+b_{p}+\frac{1}{1+r}\left[(1-f) W_{U}\left(\bar{b}, t_{c}-1,0,0\right)+f \max \left[W_{E}(w), W_{U}\left(\bar{b}, t_{c}-1,0,0\right)\right]\right] \\
W_{U}\left(\bar{b}, t_{c}, 0,0\right)= & \bar{b}+\frac{1}{1+r}\left[(1-f) W_{U}\left(\bar{b}, t_{c}-1,0,0\right)+f \max \left[W_{E}(w), W_{U}\left(\bar{b}, t_{c}-1,0,0\right)\right]\right] \\
W_{U}(\bar{b}, 1,0,0)= & \bar{b}+\frac{1}{1+r}\left[(1-f) W_{U}(0)+f \max \left[W_{E}(w), W_{U}(0)\right]\right] \\
W_{U}(0)= & \frac{f}{r+f} W_{E}(w) \\
W_{E}(w)= & w+\frac{1}{1+r}\left[(1-s) W_{E}(w)+s W_{U}\left(\bar{b}, T_{c}\right)\right]
\end{aligned}
$$


With one week and $t_{c}$ weeks of regular UI remaining and exhaustion of PUC benefits:

$$
\begin{aligned}
& W_{U}(\bar{b}, 1,0,0)=\bar{b}+\frac{f}{r+r} W_{E}(w) \\
& W_{U}\left(\bar{b}, t_{c}, 0,0\right)=\bar{b} \sum_{i=0}^{t-1}\left(\frac{1-f}{1+r}\right)^{i}+\frac{f}{r+r} W_{E}(w)=\bar{B}\left(t_{c}\right)+\frac{f}{r+r} W_{E}(w)
\end{aligned}
$$

With $t_{c}$ weeks of regular UI payments and one week of PUC payments:

$$
\begin{aligned}
& W_{U}\left(\bar{b}, t_{c}, b_{p}, 1\right)=\bar{b}+b_{p}+\frac{1}{1+r}\left[(1-f) W_{U}\left(\bar{b}, t_{c}-1,0,0\right)+f W_{E}(w)\right] \\
& W_{U}\left(\bar{b}, t_{c}, b_{p}, 1\right)=\bar{B}\left(t_{c}\right)+b_{p}+\frac{f}{r+r} W_{E}(w)
\end{aligned}
$$

With $t_{c}$ weeks of regular UI payments and $t_{p}$ weeks of PUC payments:

$$
W_{U}\left(\bar{b}, t_{c}, b_{p}, t_{p}\right)=\bar{B}\left(t_{c}\right)+B_{p}\left(t_{p}\right)+\frac{f}{r+r} W_{E}(w)
$$

Reservation supplemental benefit with one week of PUC remaining $b^{r}\left(t_{c}, t_{p}=1, w\right)$ :

$$
\begin{aligned}
W_{U}\left(\bar{b}, t_{c}, b_{p}^{r}(1), 1\right) & =W_{E}(w) \\
\bar{B}\left(t_{c}\right)+b_{p}^{r}\left(1, t_{c}\right)+\frac{f}{r+r} W_{E}(w) & =W_{E}(w) \\
b_{p}^{r}\left(1, t_{c}\right) & =\frac{r}{r+f} W_{E}(w)-\bar{B}\left(t_{c}\right)
\end{aligned}
$$

Reservation supplemental benefit with two weeks of PUC remaining $b^{r}\left(t_{c}, t_{p}=2, w\right)$ :

$$
\begin{aligned}
W_{U}\left(\bar{b}, t_{c}, b_{p}^{r}(2), 2\right) & =W_{E}(w) \\
\bar{B}\left(t_{c}\right)+B_{p}(2)+\frac{f}{r+r} W_{E}(w) & =W_{E}(w) \\
b_{p}^{r}\left(2, t_{c}\right) & =\frac{\frac{r}{r+f} W_{E}(w)-\bar{B}\left(t_{c}\right)}{\sum_{i=0}^{1}\left(\frac{1-f}{1+r}\right)^{i}}
\end{aligned}
$$

Reservation supplemental benefit with $t$ weeks of PUC remaining $b^{r}\left(t_{c}, t_{p}=t, w\right)$ :

$$
\begin{aligned}
W_{U}\left(\bar{b}, t_{c}, b_{p}^{r}(t), t\right) & =W_{E}(w) \\
\bar{B}\left(t_{c}\right)+B_{p}(t)+\frac{f}{r+r} W_{E}(w) & =W_{E}(w) \\
b_{p}^{r}\left(t, t_{c}\right) & =\frac{\frac{r}{r+f} W_{E}(w)-\bar{B}\left(t_{c}\right)}{\sum_{i=0}^{t-1}\left(\frac{1-f}{1+r}\right)^{i}}
\end{aligned}
$$




\section{B Data}

Unemployment duration is the inverse of the weekly job finding rate calculated by converting the monthly flow rate $f_{m}=U E_{t} / U_{t-1}$, to a weekly frequency as $f_{w}=1-\left(1-f_{m}\right)^{1 / 4}$; The duration of an employment spell is the inverse of the weekly job separation rate calculated from the monthly flow rate $s_{m}=\left(E U_{t}+E N_{t}\right) / E_{t-1}$, converted to a weekly rate by solving $s=s_{w}\left\{\left[\left(1-f_{w}\right)+\left(1-s_{w}\right)\right]\left(2 s_{w} f_{w}+\left(1-f_{w}\right)^{2}+\left(1-s_{w}\right)^{2}\right)\right\}$.

Table A1: Measures of weekly earnings, unemployment and employment duration

\begin{tabular}{|c|c|c|c|c|c|c|}
\hline & \multicolumn{2}{|c|}{ Weekly earnings } & \multicolumn{3}{|c|}{ Duration of: unemployment ${ }^{a}$} & \multirow{3}{*}{$\begin{array}{c}\text { employment }^{b} \\
\text { Flow } \\
1 / s_{w} \\
\end{array}$} \\
\hline & \multirow[b]{2}{*}{ mean } & \multirow[b]{2}{*}{ median } & \multicolumn{2}{|c|}{ Reported } & \multirow{2}{*}{$\begin{array}{l}\text { Flow } \\
1 / f_{w} \\
\end{array}$} & \\
\hline & & & mean & cond. on U-E & & \\
\hline Overall & 807 & 641 & 31.74 & 20.53 & 21.84 & 1.82 \\
\hline Age 25 to 54 years & 875 & 720 & 33.73 & 22.12 & 21.31 & 2.52 \\
\hline \multicolumn{7}{|l|}{ Education: } \\
\hline Less then HS & 397 & 350 & 28.56 & 18.37 & 23.19 & 0.80 \\
\hline High School & 659 & 560 & 32.46 & 21.06 & 22.09 & 1.76 \\
\hline College and above & 1174 & 1000 & 32.80 & 21.10 & 19.97 & 3.08 \\
\hline \multicolumn{7}{|l|}{ Occupation: } \\
\hline Construction & 800 & 692 & - & 18.91 & 22.09 & 0.94 \\
\hline Food Service & 352 & 300 & - & 16.91 & 21.21 & 1.19 \\
\hline Information Technology & 1374 & 1185 & - & 20.64 & 19.82 & 5.09 \\
\hline Janitors & 438 & 388 & - & 22.85 & 22.77 & 1.01 \\
\hline Managers & 1340 & 1154 & - & 23.90 & 21.00 & 3.51 \\
\hline Medical Assistants & 548 & 449 & - & 16.70 & 21.31 & 2.09 \\
\hline Nurses and Therapists & 884 & 788 & - & 16.37 & 20.33 & 3.87 \\
\hline Sales and Retail & 671 & 480 & - & 21.09 & 21.25 & 1.69 \\
\hline Teachers & 936 & 865 & - & 17.85 & 19.63 & 2.34 \\
\hline Transportation & 735 & 615 & - & 20.33 & 22.81 & 1.79 \\
\hline
\end{tabular}

Notes: (a) weeks; (b) years. Earnings data calculated using the Dec. 2018 to Dec. 2019 CPS. Durations calculated using Dec. 2009 to Dec. 2010 CPS. $w$ : weekly earnings; Weekly job finding $f_{w}$ and separation $s_{w}$ rates calculated by converting the monthly flow rates to a weekly frequency.

Job finding rates by major occupation are obtain from a logit on the outcome of a transition from unemployment into employment, $f=\exp \left(\beta_{f} X\right) /\left[1+\exp \left(\beta_{f} X\right)\right]$, based on a set of demographic characteristics in the vector $X$ that includes age, education, race/ethnicity, sex and marital status. The regression results are reported in Table A2. 
Table A2: Predicting Finding and Separation Rates for 2010

\begin{tabular}{|c|c|c|c|c|}
\hline \multirow[b]{2}{*}{ Age } & \multicolumn{2}{|c|}{$U E$} & \multicolumn{2}{|c|}{$E U+E N$} \\
\hline & & & & \\
\hline \multirow[t]{2}{*}{$25-34$} & 0.0128 & -0.0539 & -0.953 & -0.833 \\
\hline & $(0.0341)$ & $(0.0362)$ & $(0.0215)$ & $(0.0227)$ \\
\hline \multirow[t]{2}{*}{$35-44$} & -0.0316 & -0.135 & -1.166 & -0.976 \\
\hline & $(0.0356)$ & $(0.0408)$ & $(0.0222)$ & $(0.0257)$ \\
\hline \multirow[t]{2}{*}{$45-54$} & -0.195 & -0.310 & -1.274 & -1.070 \\
\hline & $(0.0363)$ & $(0.0430)$ & $(0.0220)$ & $(0.0263)$ \\
\hline \multirow[t]{2}{*}{$55-64$} & -0.333 & -0.460 & -0.970 & -0.757 \\
\hline & $(0.0437)$ & $(0.0504)$ & $(0.0230)$ & $(0.0275)$ \\
\hline \multirow[t]{2}{*}{$65-79$} & -0.468 & -0.604 & -0.0557 & 0.159 \\
\hline & $(0.0759)$ & $(0.0812)$ & $(0.0268)$ & $(0.0315)$ \\
\hline \multicolumn{5}{|l|}{ Education } \\
\hline \multirow[t]{2}{*}{ H.S. Diploma } & 0.0721 & 0.0755 & -0.536 & -0.529 \\
\hline & $(0.0336)$ & $(0.0336)$ & $(0.0211)$ & $(0.0211)$ \\
\hline \multirow[t]{2}{*}{ Some College } & 0.149 & 0.170 & -0.672 & -0.672 \\
\hline & $(0.0355)$ & $(0.0356)$ & $(0.0214)$ & $(0.0215)$ \\
\hline \multirow[t]{2}{*}{ College Degree \& Above } & 0.287 & 0.309 & -1.020 & -1.014 \\
\hline & $(0.0408)$ & $(0.0410)$ & $(0.0236)$ & $(0.0236)$ \\
\hline \multicolumn{5}{|l|}{ Race/Ethnicity } \\
\hline \multirow[t]{2}{*}{ Black } & -0.373 & -0.343 & 0.408 & 0.356 \\
\hline & $(0.0353)$ & $(0.0357)$ & $(0.0221)$ & $(0.0224)$ \\
\hline \multirow[t]{2}{*}{ Hispanic } & 0.147 & 0.137 & 0.269 & 0.268 \\
\hline & $(0.0322)$ & $(0.0323)$ & $(0.0209)$ & $(0.0209)$ \\
\hline \multirow[t]{2}{*}{ Asian/Pacific Islander } & -0.248 & -0.260 & 0.147 & 0.141 \\
\hline & $(0.0635)$ & $(0.0637)$ & $(0.0338)$ & $(0.0338)$ \\
\hline \multirow[t]{2}{*}{ Other } & -0.0771 & -0.0627 & 0.291 & 0.267 \\
\hline & $(0.0623)$ & $(0.0624)$ & $(0.0403)$ & $(0.0404)$ \\
\hline \multicolumn{5}{|l|}{ Sex } \\
\hline \multirow[t]{2}{*}{ Female } & & -0.169 & & 0.0984 \\
\hline & & $(0.0238)$ & & $(0.0141)$ \\
\hline \multicolumn{5}{|l|}{ Marital Status } \\
\hline \multirow[t]{2}{*}{ Married (Spouse Absent) } & & 0.243 & & 0.221 \\
\hline & & $(0.0866)$ & & $(0.0572)$ \\
\hline \multirow[t]{2}{*}{ Widowed } & & -0.0420 & & 0.109 \\
\hline & & $(0.0962)$ & & $(0.0465)$ \\
\hline \multirow[t]{2}{*}{ Divorced } & & -0.133 & & 0.0810 \\
\hline & & $(0.0393)$ & & $(0.0254)$ \\
\hline \multirow[t]{2}{*}{ Separated } & & 0.00183 & & 0.213 \\
\hline & & $(0.0669)$ & & $(0.0477)$ \\
\hline Never Married & & -0.185 & & 0.291 \\
\hline & & $(0.0323)$ & & $(0.0195)$ \\
\hline Constant & -1.540 & -1.314 & -1.761 & -2.070 \\
\hline & $(0.0323)$ & $(0.0450)$ & $(0.0210)$ & $(0.0277)$ \\
\hline Observations & 52442 & 52442 & 536849 & 536849 \\
\hline
\end{tabular}

Note: Groups "16-24", "Less than H.S. Diploma”, "White”, "Male”, and "Married

(Spouse Present)" are included as reference categories, respectively. 


\section{Additional tables and figures}

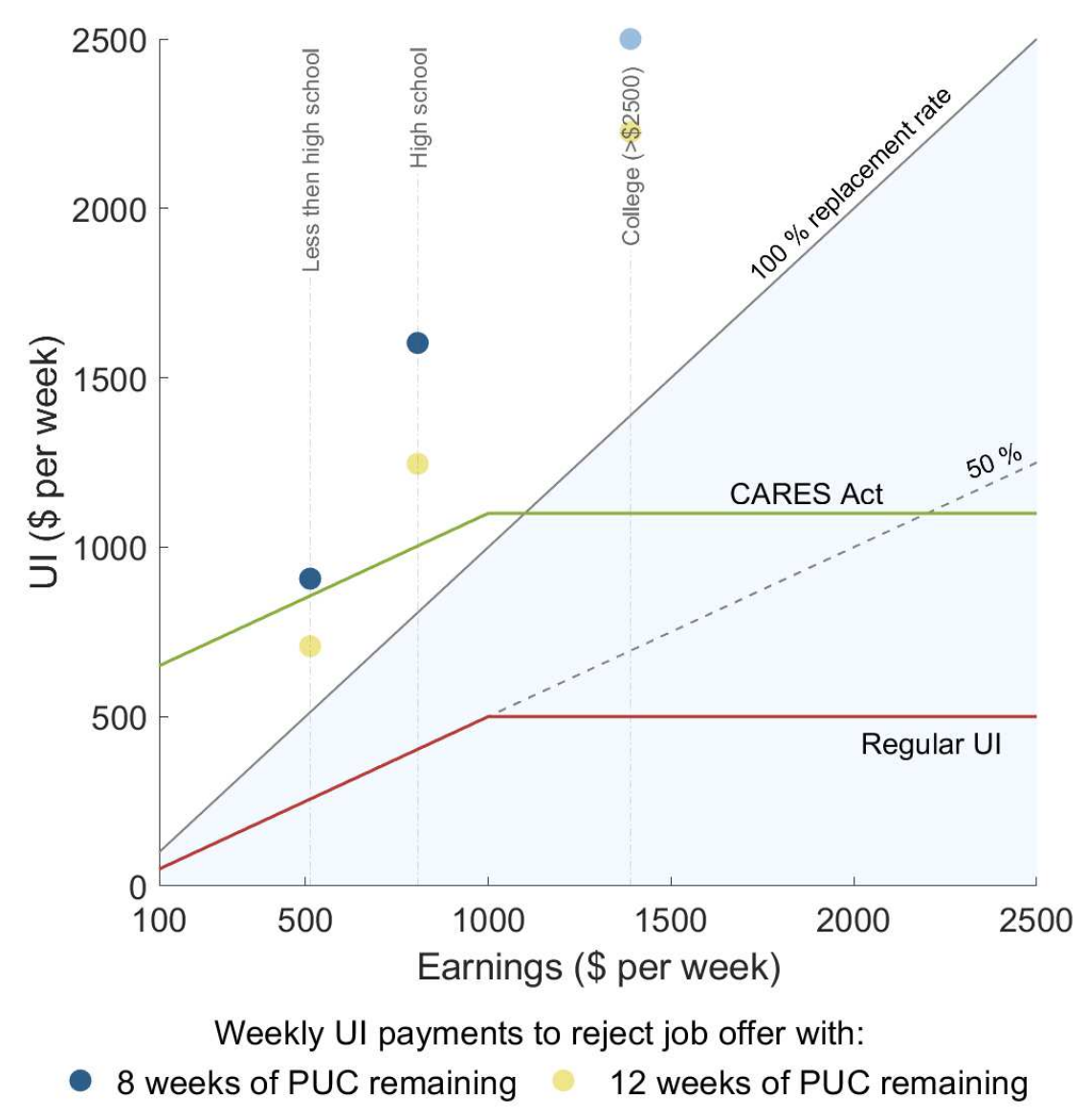

Figure A1: Regular, CARES Act and reservation level UI benefit payments - baseline

Notes: Each dot corresponds to the reservation benefit for an average worker of a particular level of educational attainment calculated according to (12) with 12 (first week of May 2020) or 8 (first week of June 2020) weeks of PUC payments remaining. 
Table A3: Reservation benefits and replacement rates - quicker re-opening

\begin{tabular}{|c|c|c|c|c|c|c|c|c|c|c|c|}
\hline & \multirow{2}{*}{$\begin{array}{c}\text { Earnings } \\
w \text { (wkly) }\end{array}$} & \multicolumn{2}{|c|}{ Duration of: } & \multicolumn{4}{|c|}{ Weekly UI compensation } & \multicolumn{4}{|c|}{ Replacement rates (\%) } \\
\hline & & $U(\mathrm{wks})$ & $E$ (yrs) & $\bar{b}$ & $b^{C}$ & $b^{r}(12)$ & $b^{r}(8)$ & $\bar{\tau}$ & $\tau^{\mathrm{C}}$ & $\tau^{r}(12)$ & $\tau^{r}(8)$ \\
\hline Overall & 1007 & 13 & 1.7 & 500 & 1100 & 1238 & 1481 & 50 & 109 & 123 & 147 \\
\hline Age 25 to 54 years & 1087 & 13 & 2.5 & 500 & 1100 & 1369 & 1645 & 46 & 101 & 126 & 151 \\
\hline \multicolumn{12}{|l|}{ Education: } \\
\hline Less then HS & 513 & 14 & 0.8 & 265 & 856 & 602 & 725 & 50 & 167 & 117 & 141 \\
\hline High School & 807 & 13 & 1.5 & 403 & 1003 & 982 & 1171 & 50 & 124 & 122 & 145 \\
\hline College and above & 1389 & 13 & 2.5 & 500 & 1100 & 1798 & 2199 & 36 & 79 & 129 & 158 \\
\hline \multicolumn{12}{|l|}{ Occupation: } \\
\hline Construction & 1000 & 12 & 1.4 & 500 & 832 & 1168 & 1374 & 50 & 110 & 117 & 137 \\
\hline Food Service & 464 & 13 & 1.0 & 232 & 874 & 541 & 642 & 50 & 179 & 116 & 138 \\
\hline IT & 1466 & 12 & 3.4 & 500 & 954 & 1871 & 2271 & 34 & 75 & 128 & 155 \\
\hline Janitors & 549 & 13 & 1.0 & 274 & 1036 & 643 & 765 & 50 & 159 & 117 & 139 \\
\hline Managers & 1554 & 12 & 2.4 & 500 & 1044 & 1961 & 2388 & 32 & 71 & 126 & 154 \\
\hline Medical Assi. & 709 & 13 & 1.7 & 354 & 1100 & 862 & 1026 & 50 & 135 & 122 & 145 \\
\hline Nurses and Thrp. & 1203 & 12 & 2.9 & 500 & 1100 & 1509 & 1813 & 42 & 91 & 125 & 151 \\
\hline Sales and Retail & 873 & 12 & 1.5 & 436 & 1100 & 1038 & 1227 & 50 & 119 & 119 & 141 \\
\hline Teachers & 1090 & 12 & 1.5 & 500 & 1100 & 1295 & 1536 & 46 & 101 & 119 & 141 \\
\hline Transportation & 887 & 12 & 1.4 & 444 & 1100 & 1061 & 1258 & 50 & 118 & 120 & 142 \\
\hline
\end{tabular}

Notes: Earnings and duration data calculated using the Dec. 2018 to Dec. 2019 CPS. w: weekly earnings; Weekly job finding $f_{w}$ and separation $s_{w}$ rates calculated by converting the monthly flow rates to a weekly frequency (see appendix for details); $\bar{b}$ : regular weekly unempmloyment benefits; $b^{C}$ : weekly benefits under CARES Act, $\bar{b}+600 \$$. 
Table A4: UI payments and reservation benefits: State average worker

\begin{tabular}{|c|c|c|c|c|c|c|c|}
\hline \multirow[b]{2}{*}{ State } & \multirow[b]{2}{*}{$U(\mathrm{wks})$} & \multirow[b]{2}{*}{$E(\mathrm{yrs})$} & \multirow[b]{2}{*}{ Earnings } & \multicolumn{2}{|c|}{ UI payments } & \multicolumn{2}{|c|}{ Replacement rates } \\
\hline & & & & CARES & Reservation & CARES & Reservation \\
\hline Alabama & 25.97 & 2.08 & 944.84 & 875.00 & 2180.19 & 92.61 & 230.75 \\
\hline Alaska & 13.93 & 1.42 & 1039.19 & 970.00 & 1573.04 & 93.34 & 151.37 \\
\hline Arizona & 20.87 & 1.57 & 966.28 & 840.00 & 1858.37 & 86.93 & 192.32 \\
\hline Arkansas & 18.11 & 1.47 & 885.76 & 1042.88 & 1548.43 & 117.74 & 174.81 \\
\hline California & 22.80 & 1.36 & 1104.16 & 1050.00 & 2240.94 & 95.09 & 202.95 \\
\hline Colorado & 19.81 & 1.57 & 1089.39 & 1161.00 & 2064.46 & 106.57 & 189.51 \\
\hline Connecticut & 25.02 & 2.13 & 1105.53 & 1152.77 & 2545.33 & 104.27 & 230.24 \\
\hline Delaware & 24.41 & 1.64 & 983.48 & 1000.00 & 2106.64 & 101.68 & 214.20 \\
\hline Florida & 27.66 & 1.70 & 945.51 & 875.00 & 2212.75 & 92.54 & 234.03 \\
\hline Georgia & 25.85 & 1.55 & 991.11 & 965.00 & 2186.48 & 97.37 & 220.61 \\
\hline Hawaii & 20.74 & 1.78 & 1000.42 & 1219.31 & 1947.56 & 121.88 & 194.67 \\
\hline Idaho & 15.72 & 1.55 & 877.42 & 1038.71 & 1419.68 & 118.38 & 161.80 \\
\hline Illinois & 24.04 & 1.70 & 1058.60 & 1084.00 & 2282.95 & 102.40 & 215.66 \\
\hline Indiana & 22.02 & 1.72 & 927.93 & 990.00 & 1869.44 & 106.69 & 201.46 \\
\hline Iowa & 17.40 & 1.94 & 909.00 & 1081.00 & 1596.55 & 118.92 & 175.64 \\
\hline Kansas & 17.43 & 1.88 & 936.40 & 1088.00 & 1641.58 & 116.19 & 175.31 \\
\hline Kentucky & 20.95 & 1.47 & 904.17 & 1122.00 & 1728.68 & 124.09 & 191.19 \\
\hline Louisiana & 17.56 & 1.49 & 935.23 & 847.00 & 1607.74 & 90.57 & 171.91 \\
\hline Maine & 20.97 & 1.77 & 914.90 & 1045.00 & 1792.67 & 114.22 & 195.94 \\
\hline Maryland & 20.13 & 1.78 & 1186.25 & 1030.00 & 2344.59 & 86.83 & 197.65 \\
\hline Massachusetts & 28.25 & 1.84 & 1154.46 & 1177.23 & 2846.98 & 101.97 & 246.61 \\
\hline Michigan & 28.24 & 1.71 & 988.07 & 962.00 & 2347.61 & 97.36 & 237.60 \\
\hline Minnesota & 19.65 & 2.03 & 1041.75 & 1120.87 & 2004.20 & 107.60 & 192.39 \\
\hline Mississippi & 25.39 & 1.59 & 846.83 & 835.00 & 1853.06 & 98.60 & 218.82 \\
\hline Missouri & 21.46 & 1.61 & 957.18 & 920.00 & 1880.86 & 96.12 & 196.50 \\
\hline Montana & 16.34 & 1.44 & 886.34 & 1060.90 & 1455.23 & 119.69 & 164.18 \\
\hline Nebraska & 17.07 & 2.05 & 916.36 & 1040.00 & 1598.51 & 113.49 & 174.44 \\
\hline Nevada & 24.77 & 1.35 & 941.18 & 1069.00 & 1973.61 & 113.58 & 209.69 \\
\hline New Hampshire & 20.21 & 2.03 & 1080.92 & 1027.00 & 2135.58 & 95.01 & 197.57 \\
\hline New Jersey & 24.42 & 1.52 & 1153.97 & 1292.38 & 2509.16 & 111.99 & 217.44 \\
\hline New Mexico & 21.88 & 1.26 & 883.68 & 1061.00 & 1697.00 & 120.07 & 192.04 \\
\hline New York & 20.51 & 1.45 & 1093.88 & 1104.00 & 2096.51 & 100.93 & 191.66 \\
\hline North Carolina & 24.90 & 1.80 & 967.19 & 950.00 & 2127.43 & 98.22 & 219.96 \\
\hline North Dakota & 10.38 & 2.09 & 976.31 & 1088.16 & 1307.54 & 111.46 & 133.93 \\
\hline Ohio & 23.02 & 1.79 & 968.19 & 1080.00 & 2018.68 & 111.55 & 208.50 \\
\hline Oklahoma & 17.83 & 1.63 & 912.10 & 1115.53 & 1597.44 & 122.30 & 175.14 \\
\hline Oregon & 23.31 & 1.77 & 1017.07 & 1248.00 & 2143.49 & 122.70 & 210.75 \\
\hline Pennsylvania & 22.92 & 1.78 & 1013.57 & 1118.47 & 2111.67 & 110.35 & 208.34 \\
\hline Rhode Island & 27.77 & 1.90 & 1050.95 & 1126.00 & 2532.72 & 107.14 & 240.99 \\
\hline South Carolina & 23.29 & 1.48 & 930.02 & 926.00 & 1904.25 & 99.57 & 204.75 \\
\hline South Dakota & 14.32 & 1.75 & 920.61 & 1014.00 & 1430.07 & 110.14 & 155.34 \\
\hline Tennessee & 23.34 & 1.81 & 929.56 & 875.00 & 1959.49 & 94.13 & 210.80 \\
\hline Texas & 17.55 & 1.52 & 981.26 & 1110.26 & 1689.79 & 113.15 & 172.21 \\
\hline Utah & 16.13 & 1.55 & 919.75 & 1054.87 & 1510.50 & 114.69 & 164.23 \\
\hline Vermont & 15.24 & 1.71 & 1000.23 & 1113.00 & 1605.14 & 111.27 & 160.48 \\
\hline Virginia & 22.43 & 2.38 & 1138.18 & 978.00 & 2476.84 & 85.93 & 217.61 \\
\hline Washington & 20.84 & 1.69 & 1111.50 & 1156.31 & 2202.80 & 104.03 & 198.18 \\
\hline West Virginia & 25.80 & 1.79 & 867.80 & 1024.00 & 1953.24 & 118.00 & 225.08 \\
\hline Wisconsin & 19.96 & 2.07 & 958.91 & 970.00 & 1850.30 & 101.16 & 192.96 \\
\hline Wyoming & 13.85 & 1.65 & 938.23 & 1087.88 & 1423.91 & 115.95 & 151.76 \\
\hline
\end{tabular}

Notes: Notes: Earnings data calculated using the Dec. 2018 to Dec. 2019 CPS. Durations calculated using Dec. 2009 to Dec. 2010 CPS. w: weekly earnings; Weekly job finding and separation rates entering the resevation benefits are obtained by converting the monthly flow rates to a weekly frequency; regular weekly unempmloyment benefits calculated with the Ganong et al (2020) UI calculator; reservation benefits reported for 8 weeks of PUC payments remaining. 